\title{
The Role of Excited Oxygen Molecules in the Formation of the Secondary Ozone Layer at 87 to $97 \mathrm{~km}$
}

\author{
Kari Hänninen \\ Department of Biological and Environmental Sciences, University of Jyväskylä, Finland
}

Copyright@2018 by authors, all rights reserved. Authors agree that this article remains permanently open access under the terms of the Creative Commons Attribution License 4.0 International License

\begin{abstract}
The secondary ozone layer is located at elevations of 87 to $97 \mathrm{~km}$ in the upper mesosphere - lower thermosphere. It overlaps with the ionospheric D-layer. Daytime intensive UV radiation is dissociating $\mathrm{O}_{2}$ molecules to $\mathrm{O}$ atoms and photoexcitating $\mathrm{O}_{2}$ molecules up to $11.07 \mathrm{eV}$ level. Ozone photolysis between the wavelengths of 118.7-121.6 nm produces three oxygen atoms from one ozone molecule. Collision reactions of $\mathrm{O}_{2}\left(\mathrm{~B}^{3} \Sigma_{\mathrm{u}}^{-}\right)$and $\mathrm{O}_{2}\left(\mathrm{X}^{3} \Sigma_{\mathrm{g}}^{-}, \mathrm{v} \geq 26\right)$ with $\mathrm{O}_{2}\left(\mathrm{X}^{3} \Sigma_{\mathrm{g}}^{-}, \mathrm{v}=0\right)$ produce additional oxygen atoms. The number of oxygen atoms is maintained at such a high level that a small but significant ozone concentration survives. UV radiation weakens radically during the night. The number of $\mathrm{O}$ atoms shows no diurnal variation in the MLT. This leads to a ten-fold increase of ozone concentration over the course of the night. Dissociative recombination of $\mathrm{O}_{2}{ }^{+}$(entered via diffusion from above) and reactions of $\mathrm{O}\left({ }^{3} \mathrm{P}\right)$ atoms with excited $\mathrm{O}_{2}$ molecules generate $\mathrm{O}\left({ }^{1} \mathrm{~S}\right)$ atoms. The quenching of $\mathrm{O}\left({ }^{1} \mathrm{~S}\right) \rightarrow \mathrm{O}\left({ }^{1} \mathrm{D}\right)$ emits the green nightglow. The reactions of $\mathrm{O}\left({ }^{1} \mathrm{D}\right)$ with ozone and $\mathrm{O}_{2}$ absorption of UV nightglow produce $\mathrm{O}_{2}\left(\mathrm{c}^{1} \Sigma_{\mathrm{u}}^{-}, \mathrm{A}^{, 3} \Delta_{\mathrm{u}}\right.$ and $\left.\mathrm{A}^{3} \Sigma_{\mathrm{u}}^{+}\right)$. When these molecules relax, they emit the $\mathrm{O}_{2} \mathrm{UV}$ nightglows. The relaxations of $\mathrm{O}_{2}\left(\mathrm{a}^{1} \Delta_{\mathrm{g}}\right)$ and $\mathrm{O}_{2}\left(\mathrm{~b}^{1} \Sigma_{\mathrm{g}}^{+}\right)$emit infrared nightglows.
\end{abstract}

Keywords Secondary Ozone Zone, Photoexcitation of $\mathrm{O}_{2}$, Vibrational and Electronical Excitation of $\mathrm{O}_{2}, \mathrm{O}_{2}{ }^{+}$ Dissociative Recombination, Nightglows

\section{Introduction}

Before the 1970s, the mesospheric-lower thermospheric (MLT) layer was located too far from the ground for the purposes of obtaining good observation results. On the other hand, for rocket research it was located too near, as they were targeting objects that were further away. Thomas and Bowman [1] examined the diurnal variations of constituents in an oxygen-hydrogen atmosphere. They compared the results of available experimental data, and suggested that their laboratory tests demonstrated atmospheric oxygen chemistry in the Schumann-Runge band region as well.

Hays and Roble [2] found that stellar ultraviolet light near $2500 \AA$ is attenuated in the Earth's upper atmosphere in the 60 - to $100-\mathrm{km}$ region due to strong absorption in the Hartley continuum of ozone. They found that the night-time ozone number density has a bulge in its vertical profile with a peak of 1 to $2 \times 10^{8} \mathrm{~cm}^{-3}$ at approximately $83 \mathrm{~km}$ and a minimum near $75 \mathrm{~km}$.

Miller and Ryder [3] also measured the concentration of ozone in the mesosphere and lower thermosphere at sunset using the occultation technique. They found a minimum in the $\mathrm{O}_{3}$ concentration near $80 \mathrm{~km}$ and a secondary $\mathrm{O}_{3}$ maximum around $90 \mathrm{~km}$.

Nowadays, there is a special Global Ozone Monitoring by Occultation of Stars (GOMOS) instrument on board the European Space Agency's Envisat satellite. This instrument measures ozone using the stellar occultation method [5]. The number density of ozone has a strong maximum region around $90 \mathrm{~km}$ (see Figure 1). This is known as the secondary ozone maximum [5, 6]. The night-time mixing ratio of ozone in this maximum zone is comparable to that found in the stratospheric maximum (around 8 to $9 \mathrm{ppm}$ ). Daytime mixing ratios are substantially smaller but are significantly higher than those observed elsewhere above or (immediately) below [5, 7].

Rogers et al. [8] measured the ozone in a layer of 80 to $104 \mathrm{~km}$ by the microwave line of $11.072454 \mathrm{GHz}$. The Gaussian distribution of the ozone mixing ratio was centred at $92 \mathrm{~km}$ with the full width at maximum of $10 \mathrm{~km}$. The location of the secondary ozone maximum can be set between altitudes of 87 to $97 \mathrm{~km}$. An important detail is that this ozone layer is a part of the ionospheric D-region as well [9]. 

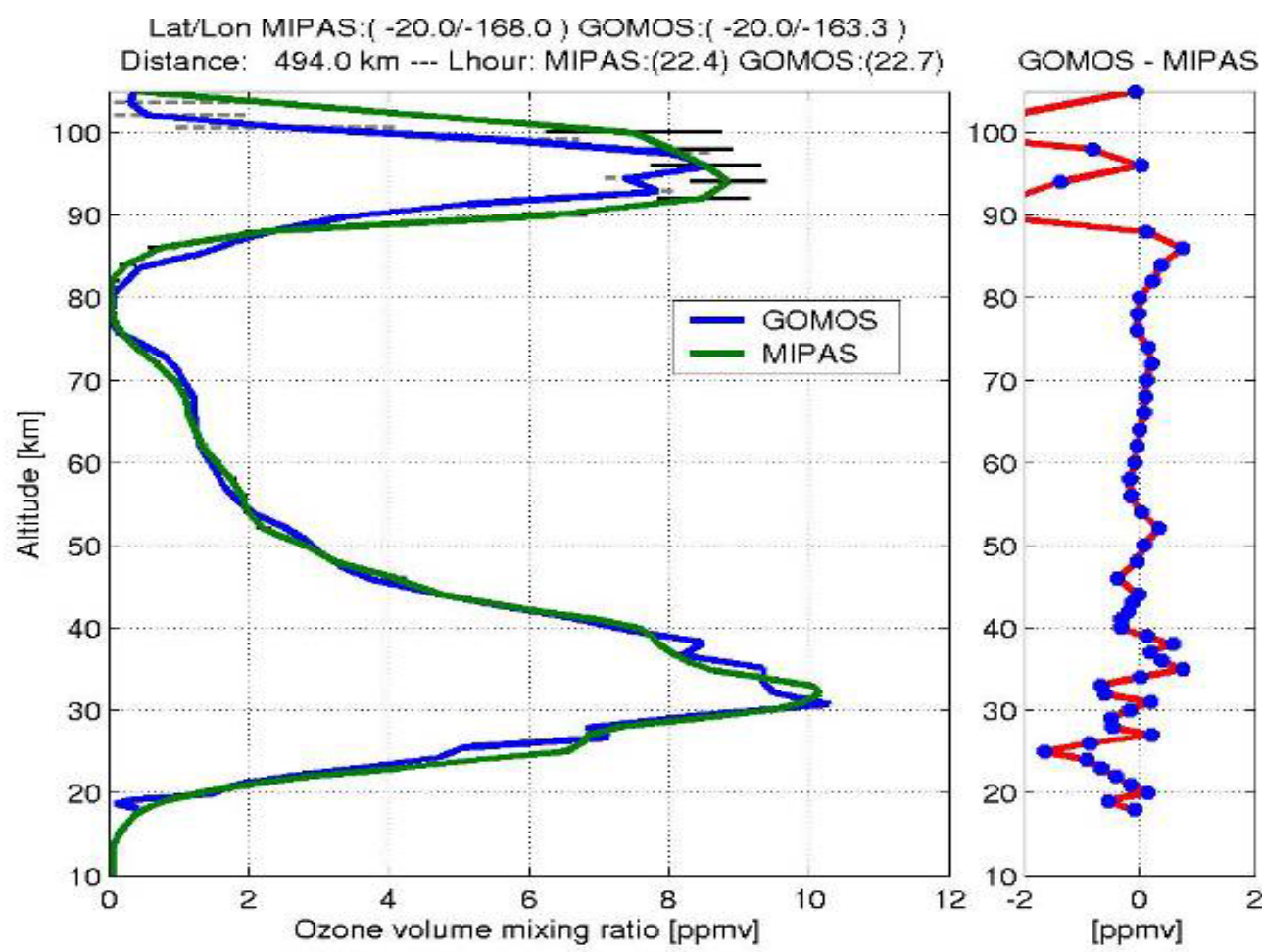

Figure 1. Variation of ozone concentration according to the height [4]

\section{Materials and Methods}

\subsection{Aims of the Study}

The aim of this meta-study is to provide a basic understanding of the formation and dynamics of energetically excited oxygen molecules, and of their importance in the generation of the secondary ozone layer. The study is based on the available literature of excited $\mathrm{O}_{2}$ molecules and excited $\mathrm{O}$ atoms in the secondary ozone layer. Data from the literature regarding atmospheric nightglows on Earth and Venus are used as crucial evidence.

\subsection{Formulas Used in Calculations}

The formation enthalpies of reactions are calculated by formula (1). If difference $\Delta \mathrm{H}^{0}<0$, reaction is proceeding spontaneously, it is an exergonic reaction.

$$
\begin{array}{r}
\left(\Delta \mathrm{H}^{0}{ }_{1}+\Delta \mathrm{H}^{0}{ }_{2}\right) \text { end products }-\left(\Delta \mathrm{H}^{0}{ }_{1}+\Delta \mathrm{H}^{0}{ }_{2}\right) \text { starting products } \\
=\Delta \mathrm{H}^{0}
\end{array}
$$

Relationship between energy and wavelength of electromagnetic radiation (EMR) is calculated by formula (2) [10].

$$
\lambda=\mathrm{hcN}_{\mathrm{A}} / \mathrm{E}
$$

The formations of enthalpies $(\mathrm{kJ} / \mathrm{mol})$ are: for ozone 142.7, for O $\left({ }^{3} \mathrm{P}\right) 249.2$, for $\mathrm{O}\left({ }^{1} \mathrm{D}\right) 438.9$ and for $\mathrm{O}\left({ }^{1} \mathrm{~S}\right) 653$. The relationships between energy units $\mathrm{eV}, \mathrm{kJ} / \mathrm{mol}$ and $\mathrm{cm}^{-1}$ are $1 \mathrm{eV}=96.49 \mathrm{~kJ} / \mathrm{mol}=8064 \mathrm{~cm}^{-1}[11]$.

\section{Discussion}

\subsection{Number Densities of Oxygen Atom in the MLT}

According to Lin et al. [12] at an altitude of about 101 $\mathrm{km}$ the model-dependent peak of atomic oxygen density is $3.6( \pm 1.9) \times 10^{11} \mathrm{~cm}^{-3}$ (or in terms of the number of atomic oxygen $\left.4.5 \times 10^{11}\right)$. In a later study by Hedin et al. [13] the maximum concentration of atomic oxygen $\left(4.7 \times 10^{11}\right.$ atoms in cubic $\mathrm{cm}$ ) was achieved at an altitude of $95 \mathrm{~km}$.

At an altitude of $105 \mathrm{~km}$, the number density of $\mathrm{O}$ atoms is $2.8 \times 10^{11}$, at an altitude of $120 \mathrm{~km}$ it is $8 \times 10^{10}$ and at an altitude of $150 \mathrm{~km}$ it is $8 \times 10^{9}$ [14]. The number of $\mathrm{O}$ atoms reaches their atmospheric maximum in the MLT. At an altitude of $120 \mathrm{~km}$ the number density of $\mathrm{O}_{2}$ molecules is 6 $x 10^{10}$ [14], which is less than the number density of $\mathrm{O}$ atoms. At an altitude of $91 \mathrm{~km}$ the number of atomic oxygen is $1.4 \times 10^{11}$ during night and day [12].

\subsection{Absorption of UV, Visible and IR Radiation by Oxygen Species}

In the thermosphere, solar UV radiation is absorbed via photoionization by hydrogen, oxygen and nitrogen atoms and molecules and helium atoms. It leads to almost complete absorption of UV radiation shorter than $102 \mathrm{~nm}$ in the thermosphere above the MLT layer.

In order to be photodissociated or photoexcitated by a 
non-ionizing photon, a molecule must absorb on the wavelength of the photon. These absorptions define the absorptive optical thickness of the atmosphere towards the UV radiation.

Oxygen atoms absorb UV radiation at wavelengths between 10nm and 91nm [15]. An oxygen atom has the ground state $\mathrm{O}\left({ }^{3} \mathrm{P}\right)$, which is a triplet state. Higher energy forms, singlet oxygen atoms, are formed if the electrons pair up, like in the first excited state $\mathrm{O}\left({ }^{1} \mathrm{D}\right)$ and second excited state $\mathrm{O}\left({ }^{1} \mathrm{~S}\right)$. Radiative lifetime of $\mathrm{O}\left({ }^{1} \mathrm{~S}\right)$ is only $0.84 \mathrm{~s}$ and that of $\mathrm{O}\left({ }^{1} \mathrm{D}\right)$ is $114 \mathrm{~s}$ [16].

Oxygen molecule absorbs UV radiation at wavelengths from 58 to $260 \mathrm{~nm}$. The absorption cut-off of UV photons by $\mathrm{O}_{2}$ molecules is $260 \mathrm{~nm}$ in $1 \mathrm{~atm}$. air pressure and $250 \mathrm{~nm}$ in zero pressure [17].
For dissociation, a photon must have so much energy that it exceeds the dissociation energy of the molecule. Due to the properties of the electron configuration, the excited $\mathrm{O}_{2}$ molecules have individual dissociation ranges within which they are more or less metastable. If the UV photon raises an electron to such a high level in which it is in the dissociation range of a certain excited state, the $\mathrm{O}_{2}$ molecule is photoexcitated rather than dissociated.

The spectrum of $\mathrm{O}_{2}$ from 102 to $125 \mathrm{~nm}$ is very complex (see Figure 2) [18]. Lyman $\beta$ line at $102.57 \mathrm{~nm}$ is known to penetrate down to about $86 \mathrm{~km}$ level [19]. The ionization potential of oxygen molecules is $12.07 \mathrm{eV}$, which is equal to the wavelength of $102.78 \mathrm{~nm} . \mathrm{O}_{2}$ molecules absorb weakly at the Lyman $\beta$ line [20] so the ionization of $\mathrm{O}_{2}$ is possible in the entire MLT layer as well.

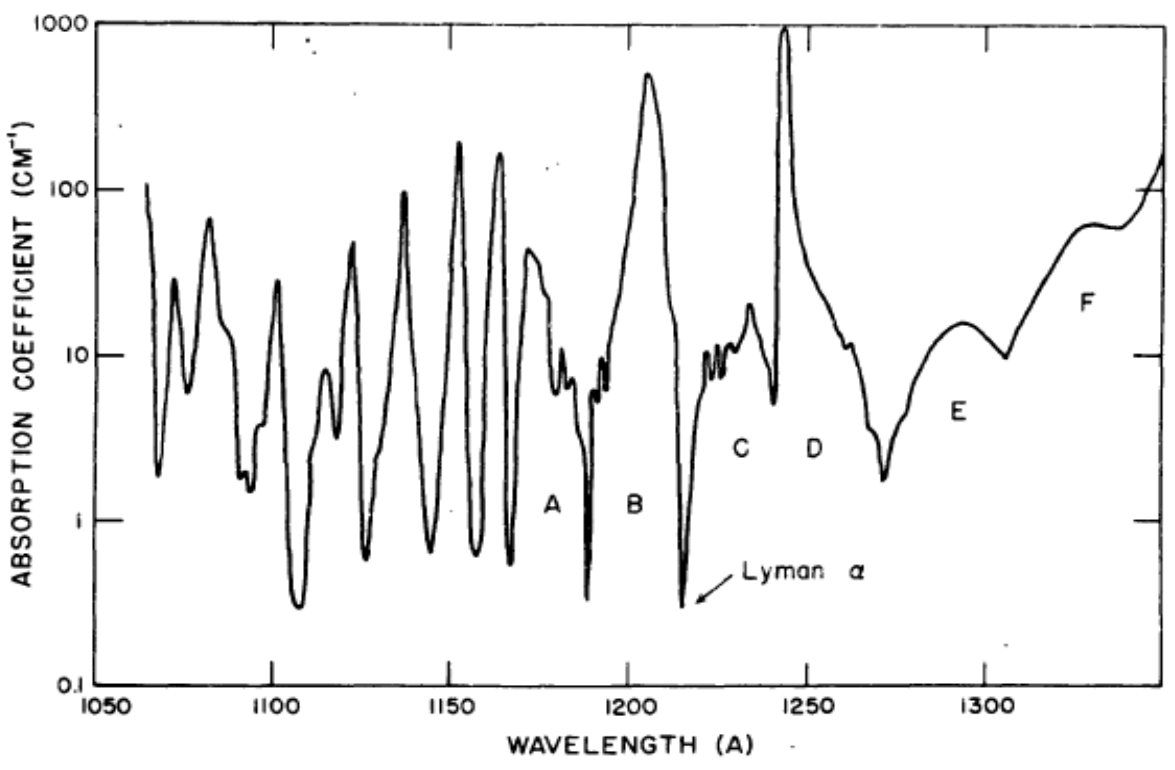

Figure 2. UV spectra of oxygen molecule at the 105 to $130 \mathrm{~nm}$ range [18] $\left(1 \mathrm{~cm}^{-1}\right.$ corresponds to a cross section of $\left.3.72 \times 10^{-22} \mathrm{~cm}^{2}\right)$

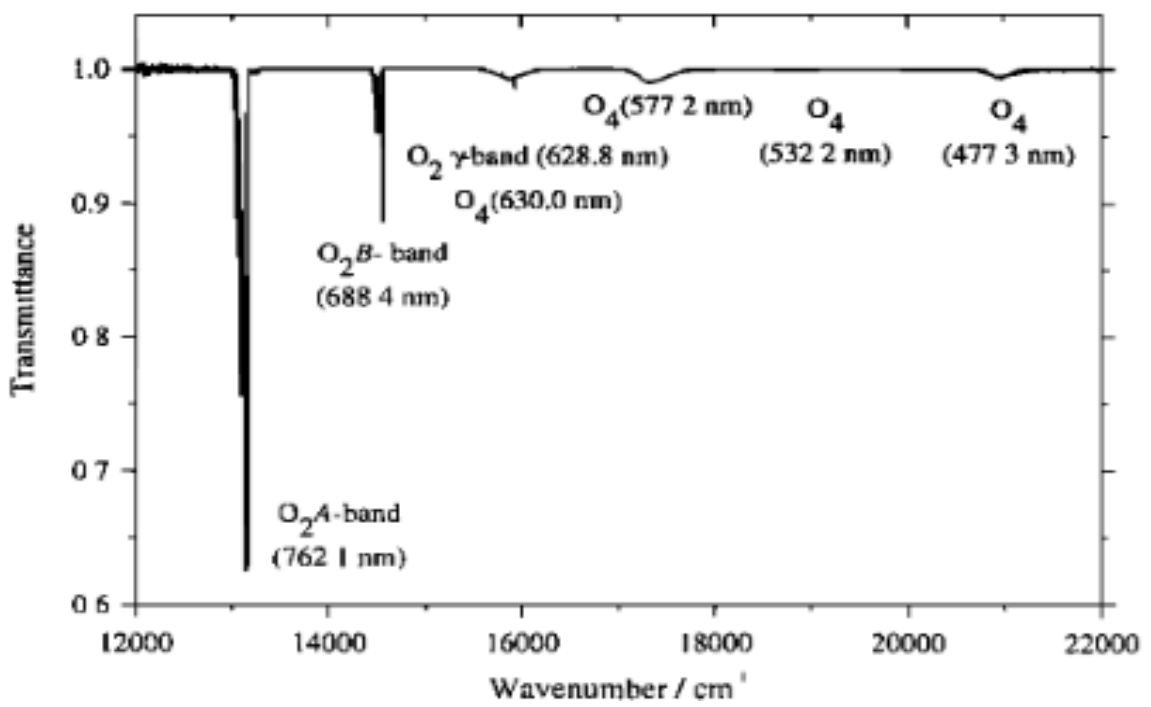

Figure 3. Survey transmittance spectrum of the visible and near IR bands of $\mathrm{O}_{2}$ [24] 
$\mathrm{UV}$ at the Lyman $\alpha$ line $(121.567 \mathrm{~nm})$ can penetrate down to $70 \mathrm{~km}$ level [19]. Even though its $\mathrm{O}_{2}$ absorption cross-section is small, about $1 \times 10^{-24} \mathrm{~cm}^{2}$ [21], it is excitating $\mathrm{O}_{2}$ molecules. Its attenuating about ten-fold between 100 to $80 \mathrm{~km}$ is, of course, mainly due to ozone molecules [19]. Between the Ly $\beta$ and Ly $\alpha$ lines, there are eight bands (centred at 107, 109. 110, 113, 114.5, 116 and $117 \mathrm{~nm}$ ) with equally small $\mathrm{O}_{2}$ UV absorption cross-sections than Lyo (see Figure 2). Especially through these windows extreme UV radiation (EUV) of 102.6 to $124 \mathrm{~nm}$ is able to enter into the MLT zone. UV photons in this range can photoexcitate highly excited $\mathrm{O}_{2}$ molecules having energies between 10.6 to $11.07 \mathrm{eV}$ (see Table 1).

Photodissociation of $\mathrm{O}_{2}$ molecules in the SchumannRunge continuum is due to the UV radiation of 125-175 $\mathrm{nm}$ [17]. This continuum is the primary source of oxygen atoms in the MLT layer and above it. UV photons at this range contain energy of 7.1 to $9.9 \mathrm{eV} / \mathrm{mol}$ (see Table 1). Products are either $\mathrm{O}\left({ }^{3} \mathrm{P}\right)$ atom + metastable $\mathrm{O}\left({ }^{1} \mathrm{D}\right)$ atom or $\mathrm{O}\left({ }^{3} \mathrm{P}\right)$ atom + metastable $\mathrm{O}\left({ }^{1} \mathrm{~S}\right)$ atom [17].

The short wavelength ends of the Schumann-Runge continuum (125-132.5 nm) UV photons photoexcitate $\mathrm{O}_{2}$ molecules with energies between 9.35 and $9.92 \mathrm{eV}$.

In the Schumann-Runge bands (175-205 nm) UV photons photoexcitate $\mathrm{O}_{2}$ molecules into the $\mathrm{O}_{2}\left(\mathrm{~B}^{3} \Sigma_{\mathrm{u}}^{-} \mathrm{v}=\right.$ $0-19)$ states of which have energies between 6.1 to 7.1eV/mol..

In the Herzberg continuum $(205<\lambda<242 \quad \mathrm{~nm})$ dissociation of $\mathrm{O}_{2}$ produces $\mathrm{O}\left({ }^{3} \mathrm{P}\right)$ atoms. When the wavelength of UV photons is $242<\lambda<252 \mathrm{~nm}$, they photoexcitate $\mathrm{O}_{2}$ molecules, having energies between 4.1 to $5.1 \mathrm{eV}[22]$.

The UV photons with $\lambda<134.1 \mathrm{~nm}$ ionize NO molecules, which fact is largely responsible for the existence of the ionospheric D-region, and it's overlapping with the MLT layer [23].

Molecular oxygen absorbs visible and near IR light as well (see Figure 3). The $\mathrm{O}_{2}$ A-band is between 12,950 and $13,200 \mathrm{~cm}^{-1}(758-772 \mathrm{~nm})$, the B-band 14,350 and 14,600 $\mathrm{cm}^{-1}(685-697 \mathrm{~nm})$, and the $\Upsilon$-band 15,700 and 15,950 $\mathrm{cm}^{-1}(627-637 \mathrm{~nm})$ [24].

Smith and Newnham [25] measured the near-infrared (NIR) absorption cross-sections and integrated absorption intensities in gas phase of oxygen and nitrogen mixtures. Monomer and binary cross-sections of the $\mathrm{O}_{2}$ $\left(\mathrm{a}^{1} \Delta_{\mathrm{g}}\right) \leftarrow \mathrm{O}_{2}\left(\mathrm{X}^{3} \Sigma_{\mathrm{g}}\right)^{-}(0,0)$ and $(1,0)$ bands and underlying continuum absorptions of oxygen were centred at 1.06 and $1.27 \mu \mathrm{m}$.

Ozone is the most important UV absorber of all oxygen species. Watanabe et al. [18] have measured the ozone UV absorption spectrum over the spectral range of 100-220 nm, and Tu and Nee [26] over the range of 105-200 nm. Ozone absorbs strongly UV radiation entering the MLT layer. Ozone absorbs visible and NIR light as well.

Recently, Gorshlev et al. [27] have measured cross-sections of ozone with great accuracy over the spectral range of 213-1100 nm. Even though UV absorption by ozone is a much studied topic, there remains disagreement regarding the absorption minimum between the Huggins and Chappuis bands (350-425 nm), and especially near $380 \mathrm{~nm}$ due to low absorption coefficients and the difficulties of preparing pure ozone for study [27].

\subsection{Basic Notations and Rules in Quantum Chemistry}

\subsubsection{Quantum Chemistry Notations}

The spectroscopic state of atoms and molecules is conveniently summarized by the use of spectroscopic term symbols. The Greek capital letters $\Sigma, \Pi$ or $\Delta$ are used as the principal symbol for the state of the molecule. It tells the resultant angular momentum of all the electrons with respect to the internuclear axis $\Lambda$, which may have values 0 , 1 and 2. When $|\Lambda|$ is 0 , the letter is $\Sigma$; when $|\Lambda|$ is 1 , the letter is $\Pi$ and when $|\Lambda|$ is 2 , the letter is $\Delta$. In atoms, the notation is analogous to the roman letters $\mathrm{S}, \mathrm{P}$ and $\mathrm{D}$. The multiplicity (singlet $=1$, triplet $=3$ ) is denoted by a superscript number to the left side of the letter $[28,29]$.

A closed molecular group, whether $\sigma$ or $\pi$, must give a ${ }^{1} \Sigma$ term, as the resultant angular momentum and the multiplicity must both be zero. A superscript + or ${ }^{-}$on the right side indicates whether the total wave function is symmetric or antisymmetric with respect to the reflection in a plane containing the principal axis. A subscript $\mathrm{g}$ or $\mathrm{u}$ on the right side is given corresponding to the gerade or ungerade molecular symmetry. The product of any number of $g$ functions or an even number of $u$ functions results in a $g$ function [28].

The lowest state of the molecule (either $\Sigma, \Pi$ or $\Delta$ ) is labelled $X$. The excited states are then labelled alphabetically, starting with A, B, and so on to indicate the first excited state, second excited state, and so on. Uppercase letters are used for states with the same multiplicity as the ground state, while lowercase letters are used for states with a different multiplicity. Occasionally, new states are found which lie in between previously assigned states. These states are labelled $\mathrm{A}^{\prime}$ or $\mathrm{B}^{\prime}$. Thus, for $\mathrm{O}_{2}$, the lowest state is $\mathrm{X}^{3} \Sigma_{\mathrm{g}}^{-}$, followed, in terms of increasing energy, by $\mathrm{a}^{1} \Delta_{\mathrm{g}}, \mathrm{b}^{1} \Sigma_{\mathrm{g}}^{+}, \mathrm{A}^{3} \Sigma_{\mathrm{u}}^{+}$and $\mathrm{B}^{3} \Sigma_{\mathrm{u}}^{-}[28$, 30].

\subsubsection{Quantum Chemical Rules: Obeyed and Disobeyed by $\mathrm{O}_{2}$ Molecules and Atoms}

Generally, according to Wigner's spin selection rules [31], chemical reactions between triplet and singlet reactants are forbidden. So the transitions $\Sigma \rightarrow \Delta, \Delta \rightarrow \Sigma$, $\Sigma^{+} \rightarrow \Sigma^{-}$and $\Sigma^{-} \rightarrow \Sigma^{+}$are forbidden. In practice, all other elements more or less obey these rules, except excited $\mathrm{O}_{2}$ molecules. Transitions (and vice versa) of $\mathrm{O}_{2}\left(\mathrm{a}^{1} \Delta_{\mathrm{g}} \rightarrow \mathrm{X}^{3} \Sigma_{\mathrm{g}}{ }^{-}\right), \quad \mathrm{O}_{2}\left(\mathrm{~A}^{3} \Sigma_{\mathrm{u}}{ }^{+} \rightarrow \mathrm{X}^{3} \Sigma_{\mathrm{g}}{ }^{-}\right)$and $\mathrm{O}_{2}\left(\mathrm{c}^{1} \Sigma_{\mathrm{g}}{ }^{-} \rightarrow\right.$ $\mathrm{X}^{3} \Sigma_{\mathrm{g}}{ }^{-}$) take place in atmosphere (see section 3.10.3).

Ground state oxygen molecules have the triplet electronic configuration whereas most natural compounds have the singlet multiplicity. The triplet multiplicity of $\mathrm{O}_{2}$ $\left(\mathrm{X}^{3} \Sigma_{\mathrm{g}}{ }^{-}\right)$is the reason why most reactions of oxygen 
molecules with organic substances do not, despite being exergonic, proceed spontaneously at room temperature. Instead, heating or a catalyst is needed [32]. The ground state $\mathrm{O}_{2}$ molecule follows strictly this quantum chemical rule. It is of vital importance for life on Earth.

Due to excitation, $\mathrm{O}_{2}$ molecules have extra energy, with the aid of which they are able to go against the quantum chemical rules. Of course, transitions/reactions may be slower and yields may subsequently be smaller than in the allowed reactions. Nature has overcome this issue by the set-up of two ozone layers in the atmosphere. The outcome is that no harmful UV radiation is able to enter the troposphere through both of them. Only that part of UV radiation that helps our body to produce D-vitamin, and which is so vital for human life, is able to enter [33]. $\mathrm{O}_{2}$ is called a life supporting and saving molecule for a reason.

In the 1980s chemical models predicted a lower density for ozone in the MLT layer than that which was observed [34]. One reason for this may have been that the quantum chemical rules of forbidden transitions/reactions for oxygen species were taken too literally in the chemical models of those times.

\subsection{Importance of $\mathrm{O}_{2}$ Vibrational Energies}

Molecular vibrations are caused by thermal infrared wavelengths and molecular rotations are caused by microwave and far-IR wavelengths. The vibrational energy levels $\mathrm{E}(v)$ within one electronic state $\left(E_{\mathrm{el}}\right)$ are schematically described by the Morse potential energy curve [35]. Vibrational energies are typically much smaller than electronical energies, and rotational energies $\mathrm{E}(\mathrm{J})$ are much smaller than vibrational energies.

However, the $\mathrm{E}(\mathrm{v})$ levels of $\mathrm{O}_{2}$ molecules contain relatively much energy. $\mathrm{O}_{2}\left(\mathrm{X}^{3} \Sigma_{\mathrm{g}}{ }^{-}\right)$possibly has up to 29 vibrationally excited states [36]. Slanger and Cosby [37] have determined the vibrational energy content of 14 of them. For example, at the level of $v=1$ the energy content of $\mathrm{O}_{2}\left(\mathrm{X}^{3} \Sigma_{\mathrm{g}}{ }^{-}\right)$is $1553 \mathrm{~cm}^{-1}(18.6 \mathrm{~kJ} / \mathrm{mol})$, at the level of $v=$ 8 it is $11803 \mathrm{~cm}^{-1}(141.2 \mathrm{~kJ} / \mathrm{mol})$ and at the level $v=14$ it is $19693 \mathrm{~cm}^{-1}(235.6 \mathrm{~kJ} / \mathrm{mol})$.

Energy of $\mathrm{O}_{2}\left(\mathrm{a}^{1} \Delta_{\mathrm{g}}, \mathrm{v}=0\right)$ is $94.3 \mathrm{~kJ} / \mathrm{mol}$ and that of $\mathrm{O}_{2}$ $\left(a^{1} \Delta_{g}, v=1\right)$ is $112.3 \mathrm{~kJ} / \mathrm{mol}$. So vibrational energy is as much as $19 \%$ from the $\mathrm{E}_{\mathrm{el}}$ of the $\mathrm{O}_{2}\left(\mathrm{a}^{1} \Delta_{\mathrm{g}}, \mathrm{v}=1\right)$ molecule. The energy of $\mathrm{O}_{2}\left(\mathrm{a}^{1} \Delta_{\mathrm{g}}, v=10\right)$ is $19695 \mathrm{~cm}^{-1}$ or $235.7 \mathrm{~kJ} / \mathrm{mol}$ [37]. It exceeds 2.5 times the $\mathrm{E}_{\mathrm{el}}$ of the $v=0$ molecule. So in case of $\mathrm{O}_{2}$ molecules, it is necessary to deal with vibrational energies as well. For $\mathrm{O}_{2}$ molecules, E (J) is much smaller than E (v). Rotational energies are important in advanced research work regarding, for example, the identification of the emissions from differently excited oxygen molecules [38].

\subsection{Electronically Excited States of $\mathrm{O}_{2}$ Molecules}

Paul Krupenie [39] lists several electronically excited states of neutral oxygen molecules and $\mathrm{O}_{2}{ }^{+}$ions. The electronic configurations and the basic energy ( $v=0$ levels) of 20 of them are presented in Table 1.

Table 1. Some excited $\mathrm{O}_{2}$ molecules, their formation of enthalpies and dissociation energies [39]

\begin{tabular}{|c|c|c|}
\hline Excited state & $\begin{array}{l}\text { Formation enthalpy } \\
\mathrm{cm}^{-1} / \mathrm{eV}\end{array}$ & $\begin{array}{c}\text { Dissociation energy } \mathrm{D}^{\circ} \\
\mathrm{cm}^{-1} / \mathrm{eV}\end{array}$ \\
\hline $\mathrm{X}^{3} \Sigma_{\mathrm{g}}^{-}$ & 0 & $41260 / 5.12$ \\
\hline $\mathrm{a}^{1} \Delta_{\mathrm{g}}$ & 7882/0.98 & $33378 / 4.14$ \\
\hline $\mathrm{b}^{1} \Sigma_{\mathrm{g}}^{+}$ & $13121 / 1.63$ & 28139/3.49 \\
\hline $\mathrm{c}^{1} \Sigma_{\mathrm{u}}^{-}$ & $32664 / 4.05$ & $8596 / 1.07$ \\
\hline $\mathrm{A}^{\prime 1} \Delta_{\mathrm{u}}$ & $34319 / 4.26$ & $6941 / 0.86$ \\
\hline $\mathrm{A}^{3} \Sigma_{\mathrm{u}}^{+}$ & $35007 / 4.34$ & $6253 / 0.77$ \\
\hline $\mathrm{B}^{3} \Sigma_{\mathrm{u}}^{-}$ & 49358/6.12 & $7770 / 0.96$ \\
\hline$\beta^{3} \Sigma_{\mathrm{u}}^{+}$ & 75450/9.35 & \\
\hline $\mathrm{a}^{1} \Sigma_{\mathrm{u}}^{+}$ & $76262 / 9.46$ & \\
\hline${ }^{3} \Sigma_{\mathrm{u}}^{+}$ & $87369 / 10.83$ & \\
\hline${ }^{1} \Delta_{\mathrm{u}}$ & $88278 / 10.95$ & \\
\hline${ }^{1} \Pi_{u}$ & $89245 / 11.07$ & \\
\hline${ }^{3} \Pi_{\mathrm{u}}$ & $85800 / 10.64$ & \\
\hline \multicolumn{3}{|l|}{$\mathrm{O}_{2}^{+}$- ion } \\
\hline $\mathrm{X}^{2} \Pi_{\mathrm{g}}$ & $97365 / 12.07$ & $53732 / 6.66$ \\
\hline${ }^{4} \Pi_{\mathrm{ui}}$ & $129889 / 16.10$ & $21208 / 2.63$ \\
\hline $\mathrm{A}^{2} \Pi_{\mathrm{u}}$ & $137435 / 17.04$ & $13662 / 1.69$ \\
\hline $\mathrm{b}^{4} \Sigma_{\mathrm{g}}^{-}$ & $146556 / 18.17$ & $20408 / 2.53$ \\
\hline $\mathrm{C}^{2} \Delta_{\mathrm{g}}$ & $158700 / 19.68$ & $19200 / 2.38$ \\
\hline $\mathrm{B}^{2} \Sigma_{\mathrm{u}}^{-}$ & $163702 / 20.30$ & $14203 / 1.76$ \\
\hline$c^{4} \Sigma_{u}^{-}$ & $198098 / 24.56$ & \\
\hline
\end{tabular}

Cooper et al. [40] have determined the wavelengths and enthalpies for transitions/emissions of several excited $\mathrm{O}_{2}$ molecules to the ground state.

\subsubsection{The Excited States of $\mathrm{O}_{2}\left(\mathrm{X}^{3} \Sigma_{\mathrm{g}}^{-}{ }^{-}, \mathrm{a}^{1} \Delta_{\mathrm{g}}\right.$ and $\left.\mathrm{b}^{1} \Sigma_{\mathrm{g}}{ }^{+}\right)$}

The electron configuration which gives rise to the ground state for $\mathrm{O}_{2}\left(\mathrm{X}^{3} \Sigma_{\mathrm{g}}{ }^{-}\right)$, and also the first excited states of $\mathrm{O}_{2}\left(\mathrm{a}^{1} \Delta_{\mathrm{g}}\right)$ and $\mathrm{O}_{2}\left(\mathrm{~b}^{1} \Sigma_{\mathrm{g}}^{+}\right)$, is [28, 39]:

$$
\begin{array}{r}
\left(1 \sigma_{\mathrm{g}} 1 \mathrm{~s}\right)^{2}<\left(1 \sigma_{\mathrm{u}}{ }_{\mathrm{u}} 1 \mathrm{~s}\right)^{2}<\left(2 \sigma_{\mathrm{g}} 2 \mathrm{~s}\right)^{2}<\left(2 \sigma_{\mathrm{u}} 2 \mathrm{~s}\right)^{2}<\left(3 \sigma_{\mathrm{g}} 2 \mathrm{p}\right)^{2}< \\
\left(1 \pi_{\mathrm{u}} 2 \mathrm{p}\right)^{4}<\left(1 \pi^{*}{ }_{\mathrm{g}} 2 \mathrm{p}\right)^{2}
\end{array}
$$

Or, expressed as the number of electrons: 2, 2, 2, 2, 2, 4 and 2. $\left(1 \sigma_{\mathrm{g}}\right)^{2}$ and $\left(1 \sigma_{\mathrm{u}}\right)^{2}$ are inner (and virtually atomic) orbitals, usually marked with the letter K. Antibonding orbitals are marked with an asterisk while the others are bonding orbitals. $\left(2 \sigma_{\mathrm{g}}\right)^{2}$ and $\left(2 \sigma_{\mathrm{u}}\right)^{2}$ are actually modified $(2 \mathrm{~s})^{2}$-orbitals. An $\mathrm{O}_{2}$ molecule has 12 valence electrons, eight of which are bonding MOs and four are antibonding MOs.

All other orbitals no longer resemble their separated (atomic form). $\mathrm{O}_{2}\left(\mathrm{X}^{3} \Sigma_{\mathrm{g}}^{-}, \mathrm{a}^{1} \Delta_{\mathrm{g}}\right.$ and $\left.\mathrm{b}^{1} \Sigma_{\mathrm{g}}{ }^{+}\right)$molecules differ only in the spin and occupancy of oxygen's two antibonding $\left(1 \pi_{\mathrm{g}}\right)^{2}$ MOs, which are degenerate (equal in energy). The energies of $\mathrm{O}_{2}\left(\mathrm{a}^{1} \Delta_{\mathrm{g}}\right.$ and $\left.\mathrm{b}^{1} \Sigma_{\mathrm{g}}{ }^{+}\right)$are $94.3 \mathrm{~kJ} / \mathrm{mol}$ and $157 \mathrm{~kJ} / \mathrm{mol}$ respectively.

$\mathrm{O}_{2}\left(\mathrm{a}^{1} \Delta_{\mathrm{g}}, v=0\right.$ and 1$)$ are photoexcited by IR photons of $1060 \mathrm{~nm}$ and $1269 \mathrm{~nm}$ [41]. The photoexcitation of 
$\mathrm{O}_{2}\left(\mathrm{~b}^{1} \Sigma_{\mathrm{g}}^{+}\right)$takes place with visible and IR photons at the A-, $\mathrm{B}$ - and $\Upsilon$ bands of $\mathrm{O}_{2}$ (see Figure 3 ) in which the photon energy is more than $157 \mathrm{~kJ} / \mathrm{mol}$.

\subsubsection{The Excited States of $\mathrm{O}_{2}\left(\mathrm{c}^{1} \Sigma_{\mathrm{u}}{ }^{-}, \mathrm{A}^{, 1} \Delta_{\mathrm{u}}, \mathrm{A}^{3} \Sigma_{\mathrm{u}}{ }^{+}\right.$and $\mathrm{B}^{3} \Sigma_{\mathrm{u}}-$ )}

These molecules are produced when one electron is moved from bonding $\left(1 \pi_{\mathrm{u}}\right)^{4} \mathrm{MO}$ to antibonding $\left(1 \pi_{\mathrm{g}}\right)^{2} \mathrm{MO}$. The number of electrons on the last three MOs becomes $\left(3 \sigma_{\mathrm{g}}\right)^{2}=2,\left(1 \pi_{\mathrm{u}}\right)^{3}=3$ and $\left(1 \pi_{\mathrm{g}}\right)^{3}=3$ [39]. Compared to $\mathrm{O}_{2}$ $\left(\mathrm{A}^{3} \Sigma_{\mathrm{u}}{ }^{+}\right)$, the excitation of $\mathrm{O}_{2}\left(\mathrm{~B}^{3} \Sigma_{\mathrm{u}}{ }^{-}\right)$requires $171.6 \mathrm{~kJ} / \mathrm{mol}$ more energy.

Copeland et al. [22] photoexcitated $\mathrm{O}_{2}\left(\mathrm{X}^{3} \Sigma_{\mathrm{g}}{ }^{-}\right)$with a laser beam between the wavelengths 242 to $252 \mathrm{~nm}$ to $\mathrm{O}_{2}$ $\left(\mathrm{A}^{3} \Sigma_{\mathrm{u}}^{+}\right)$at vibrational levels of $v=6$ to the highest level of $v=11$. This proves that an important formation mechanism of the excited states of $\mathrm{O}_{2}\left(\mathrm{c}^{1} \Sigma_{\mathrm{u}}^{-}, \mathrm{A}^{, 1} \Delta_{\mathrm{u}}\right.$ and $\left.\mathrm{A}^{3} \Sigma_{\mathrm{u}}{ }^{+}\right)$is photoexcitation of $\mathrm{O}_{2}\left(\mathrm{X}^{3} \Sigma_{\mathrm{g}}{ }^{-}\right)$between UV cut-off and dissociation wavelengths of the $\mathrm{O}_{2}$ molecule.

The highest vibrational level of $\mathrm{O}_{2}\left(\mathrm{~A}^{3} \Sigma_{\mathrm{u}}^{+}\right)$is only 100 $\mathrm{cm}^{-1}$ (or $1.2 \mathrm{~kJ} / \mathrm{mol}$ ) from the $\mathrm{O}_{2}\left(\mathrm{X}^{3} \Sigma_{\mathrm{g}}{ }^{-}, \mathrm{v}=0\right.$ ) dissociation limit. However, the yields of $\mathrm{O}$ atoms in the dissociation of $v=11$ to was similar to that of $v=10$. This shows that within its dissociation range (see Table 1$)$, the $\mathrm{O}_{2}\left(\mathrm{~A}^{3} \Sigma_{\mathrm{u}}{ }^{+}\right)$ molecule is rather stable. It is likely that if the total energy available in a reaction of $\mathrm{O}_{2}\left(\mathrm{X}^{3} \Sigma_{\mathrm{g}}{ }^{-}\right)$fits within the dissociation limits of the $\mathrm{O}_{2}\left(\mathrm{~A}^{3} \Sigma_{\mathrm{u}}^{+}\right)$, it is likely to form.

$\mathrm{O}_{2}\left(\mathrm{a}^{1} \Delta_{\mathrm{g}}\right), \mathrm{O}_{2}\left(\mathrm{~b}^{1} \Sigma_{\mathrm{g}}{ }^{+}\right), \mathrm{O}_{2}\left(\mathrm{c}^{1} \Sigma_{\mathrm{u}}{ }^{-}\right), \mathrm{O}_{2}\left(\mathrm{~A}^{3} \Delta_{\mathrm{u}}\right)$ and $\mathrm{O}_{2}\left(\mathrm{~A}^{3} \Sigma_{\mathrm{u}}^{+}\right)$ are all metastable towards radiation, which means that they lack an efficient radiative pathway for formation and deactivation, so their lifetimes are relatively long. The lifetime of $\mathrm{O}_{2}\left(\mathrm{a}^{1} \Delta_{\mathrm{g}}\right)$ in the MLT layer is even 75 minutes [16]. According to Slanger [42], the estimated radiative lifetimes are 25-160 milliseconds for $\mathrm{O}_{2}\left(A^{3} \Sigma_{u}^{+}, v=0-6\right)$ and 25-50 seconds for $\mathrm{O}_{2}\left(c^{1} \Sigma_{u}^{-}, v=0-10\right)$. For $\mathrm{O}_{2}\left(A^{-3} \Delta_{u}\right.$ $(\Omega=1, v=0-6)$, the estimated lifetime is $5-50$ seconds, and for $\mathrm{O}_{2}\left(A^{-3} \Delta_{u}(\Omega=2, v=6)\right.$ it is $10-100$ seconds.

The $\mathrm{O}_{2}\left(\mathrm{~B}^{3} \Sigma_{\mathrm{u}}{ }^{-}\right)$molecule contains energy of $6.12 \mathrm{eV}$, which is higher than $5.12 \mathrm{eV}$, the dissociation energy of an $\mathrm{O}_{2}\left(\mathrm{X}^{3} \Sigma_{\mathrm{g}}^{-}, \mathrm{v}=0\right)$. Rotational and vibrational energy levels $\mathrm{E}(\mathrm{v}, \mathrm{J})$ above the dissociation energy can still be stable if they are below the maximum of the potential barrier. A quantum mechanical tunnelling effect is used to provide a rationale for predissociation [29].

Predissociation was first described in 1924 for sulphur molecule $S_{2}$. Typical to the phenomenon is that no rotational spectra can be resolved, even in cases when absorption maxima and minima have been observed [43]. In the emission spectrum of the oxygen molecule, no bands in the Schumann-Runge system, $\mathrm{O}_{2}\left(\mathrm{~B}^{3} \Sigma_{\mathrm{u}}{ }^{-} \rightarrow \mathrm{O}_{2}\left(\mathrm{X}^{3} \Sigma_{\mathrm{g}}{ }^{-}\right.\right.$, having $v>2$ have ever been observed. The absence of these emission bands as well as evidence of broadened rotation lines in the $v>2$ absorption bands suggests that in these vibration levels of $\mathrm{O}_{2} \quad\left(\mathrm{~B}^{3} \Sigma_{\mathrm{u}}{ }^{-}\right)$state undergo predissociation [44].

The qualitative description of the phenomenon of predissociation is considered adequate, but it is insufficient for quantitative calculations of lifetimes and dissociation probabilities [43]. That is why the radiative lifetime of $\mathrm{O}_{2}\left(\mathrm{~B}^{3} \Sigma_{\mathrm{u}}{ }^{-}\right)$remains enigmatic. Transitions in predissociation were supposed to be radiationless [44]. The wavelength range of the transition $\mathrm{O}_{2}\left(\mathrm{~B}^{3} \Sigma_{\mathrm{u}}{ }^{-} \rightarrow \mathrm{X}^{3} \Sigma_{\mathrm{g}}{ }^{-}\right)$is 211-566 nm. [45]. This would apply to molecules of $\mathrm{O}_{2}\left(\mathrm{~B}^{3} \Sigma_{\mathrm{u}}{ }^{-}, \mathrm{v}=0,1\right.$ and 2$)$. However, there is no explanation for why these states relax by radiating, but when $v$ increases $>2$, the relaxation would be radiationless.

Predissociation does not affect the energy content of $\mathrm{O}_{2}\left(\mathrm{~B}^{3} \Sigma_{\mathrm{u}}{ }^{-}\right)$. Within its $7700 \mathrm{~cm}^{-1}(92.1 \mathrm{~kJ} / \mathrm{mol})$ dissociation energy, there is room for 19 different vibronic states of $\mathrm{O}_{2}$ $\left(\mathrm{B}^{3} \Sigma_{\mathrm{u}}{ }^{-}\right)$molecules [40]. So in the supposed radiationless radiation, the $\mathrm{O}_{2}\left(\mathrm{~B}^{3} \Sigma_{\mathrm{u}}^{-}, v>2\right)$ molecules lose no energy.

When $\mathrm{O}_{2}\left(\mathrm{X}^{3} \Sigma_{\mathrm{g}}{ }^{-}, v=0\right)$ absorbs a UV photon in the Schumann-Runge bands, its internuclear distance (R) increases from the value $1.2075358 \AA$ to the value $1.6042799 \AA$ for $\mathrm{O}_{2}\left(\mathrm{~B}^{3} \Sigma_{\mathrm{u}}{ }^{-}\right)$[39]. The double bond between the oxygen atoms in the $\mathrm{O}_{2}\left(\mathrm{~B}^{3} \Sigma_{\mathrm{u}}{ }^{-}\right)$molecule probably becomes weaker. Considering the great $\mathrm{E}_{\mathrm{el}}$ and $\mathrm{E}$ (v), the $\mathrm{O}_{2}\left(\mathrm{~B}^{3} \Sigma_{\mathrm{u}}^{-}, v>2\right)$ molecules would become more exposed towards all possible collision reactions, supposing its radiative lifetime is sufficiently long.

Sick et al. [46] have actually demonstrated that $\mathrm{O}_{2}\left(\mathrm{~B}^{3} \Sigma_{\mathrm{u}}{ }^{-}\right)$ can undergo collisional reactions. It may be that due to the predissociation phenomenon (lack of rotation) the molecule internally strengthens against radiative relaxation. This would allow the $\mathrm{O}_{2}\left(\mathrm{~B}^{3} \Sigma_{\mathrm{u}}{ }^{-}, v>2\right)$ molecules to be destroyed in collisions. In this case, no emission spectra would be generated.

An increase of internuclear distance, predissociation via tunneling effect and the fact that transition $\mathrm{O}_{2}\left(\mathrm{~B}^{3} \Sigma_{\mathrm{u}}{ }^{-}\right) \leftarrow \mathrm{O}_{2}\left(\mathrm{X}^{3} \Sigma_{\mathrm{g}}{ }^{-}\right)$is optically allowed [16] are obviously important mechanisms to aid the oxygen molecule in absorbing UV radiation at the SchumannRunge bands without dissociation into two $\mathrm{O}\left({ }^{3} \mathrm{P}\right)$ atoms + excessive heat.

\subsubsection{The Excited States of $\mathrm{O}_{2}\left(\beta^{3} \Sigma_{\mathrm{u}}{ }^{+}, \mathrm{a}^{1} \Sigma_{\mathrm{u}}{ }^{+},{ }^{1} \Delta_{\mathrm{u}},{ }^{3} \Sigma_{\mathrm{u}}{ }^{+},{ }^{1} \Pi_{\mathrm{u}}\right.$ and $\left.{ }^{3} \Pi_{u}\right)$}

The molecules are formed when one electron is moved from $\left(2 \sigma_{\mathrm{g}}\right)^{2} \mathrm{MO}$ to $\left(3 \sigma_{\mathrm{u}}\right)^{2} \mathrm{MO}$. The number of electrons on the last four MOs becomes $2 \sigma_{\mathrm{g}}=1,\left(1 \pi_{\mathrm{u}}\right)^{4}=4,\left(1 \pi_{\mathrm{g}}\right)^{2}=2$ and $3 \sigma_{\mathrm{u}}=1$. In ${ }^{1} \Pi_{\mathrm{u}}$ and ${ }^{3} \Pi_{\mathrm{u}}$, one electron is moved from $1 \pi_{\mathrm{u}} \mathrm{MO}$ to $3 \sigma_{\mathrm{u}} \mathrm{MO}[39]$.

The excited oxygen molecules in this category belong to the energy range of 9.35 to $11.07 \mathrm{eV}$ (see Table 1). They are formed by direct photoexcitation: 1) UV photons of $\lambda<$ $131 \mathrm{~nm}$ produce $\mathrm{O}_{2}\left(\beta^{3} \Sigma_{\mathrm{u}}^{+}\right)$and $\mathrm{O}_{2}\left(\mathrm{a}^{1} \Sigma_{\mathrm{u}}^{+}\right)$and 2) UV photons of $\lambda<112$ produce ${ }^{3} \Sigma_{\mathrm{u}}{ }^{+},{ }^{1} \Delta_{\mathrm{u}}$ and ${ }^{1} \Pi_{\mathrm{u}}$.

England et al. [47] have made a comprehensive vibronic assignment of the $\mathrm{O}_{2}\left({ }^{3} \Pi_{\mathrm{u}}\right)$ states in the region 104 to 120 $\mathrm{nm}$. They report measurements of $17^{3} \Pi_{\mathrm{u}} \leftarrow \mathrm{X}^{3} \Sigma_{\mathrm{g}}-$ bands in the $85,800-93,000 \mathrm{~cm}^{-1}(10.64-11.53 \mathrm{eV})$ region of the photoabsorption spectra of ${ }^{16} \mathrm{O}_{2}$ and ${ }^{18} \mathrm{O}_{2}$. Lewis and Gibson [38] have measured the wavelength of the transition $\mathrm{O}_{2}\left(\beta^{3} \Sigma_{\mathrm{u}}{ }^{+}, v=3\right) \leftarrow \mathrm{O}_{2}\left(\mathrm{X}^{3} \Sigma_{\mathrm{g}}{ }^{-}\right)$to be $123.4 \mathrm{~nm}$. 
When dissociated, these $\mathrm{O}_{2}$ molecules are energetically able to produce $\mathrm{O}\left({ }^{1} \mathrm{~S}\right)$ and $\mathrm{O}\left({ }^{1} \mathrm{D}\right)$ atoms.

\subsubsection{Ionic $\mathrm{O}_{2}^{+}$Molecules}

The first of the $\mathrm{O}_{2}{ }^{+}$ions (with the lowest energy of 12.07 $\mathrm{eV})$, is $\mathrm{X}^{2} \Pi_{\mathrm{g}}$ which has lost one $1 \pi_{\mathrm{g}}$ electron. The $\mathrm{O}_{2}\left(\mathrm{a}^{4} \Pi_{\mathrm{ui}}\right)$ and $\mathrm{O}_{2}\left(\mathrm{~A}^{2} \Pi_{\mathrm{u}}\right.$, molecules have lost one $1 \pi_{\mathrm{u}}$ electron. The $\mathrm{O}_{2}\left(\mathrm{~b}^{4} \Sigma_{\mathrm{g}}{ }^{-}\right), \mathrm{O}_{2}\left(\mathrm{C}^{2} \Delta_{\mathrm{g}}\right)$ and $\mathrm{O}_{2}\left(\mathrm{~B}^{2} \Sigma_{\mathrm{u}}{ }^{-}\right)$molecules have lost one $3 \sigma_{\mathrm{g}}$ electron. The $\mathrm{O}_{2}\left(\mathrm{c}^{4} \Sigma_{\mathrm{u}}{ }^{-}\right)$molecule has lost one $2 \sigma_{\mathrm{u}}$ electron. [39]. The energy range of ionic $\mathrm{O}_{2}$ molecules is between $12.07-24.56 \mathrm{eV}$, which is equal to the wavelength range $102.7 \mathrm{~nm}-50.5 \mathrm{~nm}$.

The $\mathrm{O}_{2}{ }^{+}$ion has 11 valence electrons, of which eight are bonding electrons and three antibonding electrons. Thus, its bond order is $1 / 2(8-3)=2 \frac{1}{2}$. The experimental dissociation energy and bond length of the $\mathrm{O}_{2}\left(\mathrm{X}^{2} \Pi_{\mathrm{g}}\right)$ ion are $643 \mathrm{~kJ} / \mathrm{mol}$ and $1.123 \AA$, respectively [39]. In terms of dissociation energy, losing one electron makes the $\mathrm{O}_{2}\left(\mathrm{X}^{2} \Pi_{\mathrm{g}}\right)$ molecule "stronger" than $\mathrm{O}_{2}\left(\mathrm{X}^{3} \Sigma_{\mathrm{g}}{ }^{-}\right)$. However, the ionic $\mathrm{O}_{2}$ molecules have a "weak" side - absorption of an electron changes their bond order from 2.5 to 2.0. So a single electron with its $32.8 \mathrm{~kJ} / \mathrm{mol}$ energy [48] can dissociate ionic $\mathrm{O}_{2}\left(\mathrm{X}^{2} \Pi_{\mathrm{g}}\right)$ molecule in the dissociative recombination reaction (DR) [49]:

$$
\mathrm{O}_{2}\left(\mathrm{X}^{2} \Pi_{\mathrm{g}}\right)+\mathrm{e} \rightarrow \mathrm{O}\left({ }^{1} \mathrm{D}\right)+\mathrm{O}\left({ }^{1} \mathrm{~S}\right) ; \Delta \mathrm{H}^{0}=-105.5 \mathrm{~kJ} / \mathrm{mol}(4)
$$

The lifetime of $\mathrm{O}_{2}{ }^{+}$ions in the night depends mostly on the available electron concentration. $\mathrm{O}_{2}^{+}$ion concentrations peak at $110 \mathrm{~km}$ [23]. It is quite possible that some $\mathrm{O}_{2}\left(\mathrm{X}^{2} \Pi_{\mathrm{g}}\right)$ molecules are produced in the MLT layer and that at 110 $\mathrm{km}$, more $\mathrm{O}_{2}\left(\mathrm{X}^{2} \Pi_{\mathrm{g}}\right)$ and other $\mathrm{O}_{2}{ }^{+}$ions enter into the MLT layer via diffusion. During the night the reaction (4) may have importance, as a continuous additional source of $\mathrm{O}\left({ }^{1} \mathrm{~S}\right)$ atoms.

\subsection{Reactions of Vibrationally and Electronically Excited $\mathrm{O}_{2}$ Molecules}

\subsubsection{Vibrationally Excited $\mathrm{O}_{2}\left(\mathrm{X}^{3} \Sigma_{\mathrm{g}}{ }^{-}\right)$}

Kinetic studies by Rogaski et al. [50] and Miller et al. [51] suggest that $\mathrm{O}_{2}\left(\mathrm{X}^{3} \Sigma_{\mathrm{g}}{ }^{-}, v \geq 26\right)$ is formed in ozone photolysis via the triplet channel in the ozone photodissociation in the Hartley band with UV photons of $\lambda<233 \mathrm{~nm}$ :

$\mathrm{O}_{3}+\mathrm{h} v \rightarrow \mathrm{O}_{2}\left(\mathrm{X}^{3} \Sigma_{\mathrm{g}}^{-}, v \geq 26\right)+\mathrm{O}\left({ }^{3} \mathrm{P}\right) ; \Delta \mathrm{H}^{0}=-2 \mathrm{~kJ} / \mathrm{mol}(5)$

These vibrationally excited ground state oxygen molecules have energis $\geq 4.2 \mathrm{eV}(405 \mathrm{~kJ} / \mathrm{mol})$. It is possible that the $\mathrm{O}_{2}\left(\mathrm{X}^{3} \Sigma_{\mathrm{g}}^{-}, v \geq 26\right)$ molecules enter vibrational-to-electronic $(\mathrm{v} \rightarrow \mathrm{E})$ energy transfer reactions when colliding with a ground state $\mathrm{O}_{2}$ molecule [50]:

$\mathrm{O}_{2}\left(\mathrm{X}^{3} \Sigma_{\mathrm{g}}^{-}, \mathrm{v} \geq 26\right)+\mathrm{O}_{2}\left(\mathrm{X}^{3} \Sigma_{\mathrm{g}}^{-}\right) \rightarrow \mathrm{O}_{2}\left(\mathrm{c}^{1} \Sigma_{\mathrm{u}}^{-}\right)+\mathrm{O}_{2}\left(\mathrm{X}^{3} \Sigma_{\mathrm{g}}^{-}\right)$;

$$
\Delta \mathrm{H}^{0}=-14.2 \mathrm{~kJ} / \mathrm{mol}
$$

A theoretical problem here is that this reaction is forbidden by quantum chemical rules. However, it is known that the Herzberg II UV nightglow is due to the relaxation of $\mathrm{O}_{2}\left(\mathrm{c}^{1} \Sigma_{\mathrm{g}}{ }^{-} \rightarrow \mathrm{X}^{3} \Sigma_{\mathrm{g}}{ }^{-}\right)$. The reaction (6) would be an important night-time source of $\mathrm{O}_{2}\left(\mathrm{c}^{1} \Sigma_{\mathrm{u}}{ }^{-}\right)$for the
Hertzberg II nightglow.

A second possible channel is that $\mathrm{O}_{3}$ and $\mathrm{O}$ are formed $[50,51]$ :

$$
\begin{gathered}
\mathrm{O}_{2}\left(\mathrm{X}^{3} \Sigma_{\mathrm{g}}^{-}, v \geq 26\right)+\mathrm{O}_{2}\left(\mathrm{X}^{3} \Sigma_{\mathrm{g}}{ }^{-}\right) \\
\Delta \mathrm{H}^{0}==-13.1 \mathrm{~kJ} / \mathrm{mol}
\end{gathered}
$$

In this channel the result would be production of two unpaired oxygen species. This would be important for maintaining both the daytime and night-time ozone and oxygen atom concentration.

\subsubsection{Electronically excited $\mathrm{O}_{2}\left(\mathrm{~B}^{3} \Sigma_{\mathrm{u}}{ }^{-}\right)$}

The Schumann-Runge bands have been observed in hydrogen, carbon monoxide and ammonia flames. This suggests that there may be a reaction common to all flames such as [52]:

$$
\begin{aligned}
& \mathrm{O}\left({ }^{3} \mathrm{P}\right)+\mathrm{O}\left({ }^{1} \mathrm{D}\right)+\mathrm{M} \rightarrow \mathrm{O}_{2}\left(\mathrm{~B}^{3} \Sigma_{\mathrm{u}}{ }^{-}\right)+\mathrm{M} ; \Delta \mathrm{H}^{0}= \\
& =-97.6 \mathrm{~kJ} / \mathrm{mol}
\end{aligned}
$$

The prerequisite of reaction (8) is the participation of $\mathrm{O}$ $\left({ }^{1} \mathrm{D}\right)$ atoms, generated either via the heat of flame at the surface or via quenching of $\mathrm{O}\left({ }^{1} \mathrm{~S}\right)$ or via various reactions in the MLT layer.

Copeland et al. [22] have shown that $\mathrm{O}$ atoms are generated efficiently in the collision of vibrationally excited $\mathrm{O}_{2}\left(\mathrm{~A}^{3} \Sigma_{\mathrm{u}}^{+}, v \geq 9\right)$ with (vibrationally excited) ground state $\mathrm{O}_{2}$ (reaction 9). Collision reactions of $\mathrm{O}_{2}$ $\left(\mathrm{B}^{3} \Sigma_{\mathrm{u}}{ }^{-}\right.$) with ground state $\mathrm{O}_{2}$ molecules (reaction 10) is also allowed by quantum chemical rules, and is so even more likely. If $\mathrm{O}_{2}\left(\mathrm{X}^{3} \Sigma_{\mathrm{g}}^{-}\right)$is vibrationally excited $(v \geq 26)$ it is energetically possible that $O\left({ }^{1} S\right)$ is formed (reaction 11):

$$
\begin{gathered}
\mathrm{O}_{2}\left(\mathrm{~A}^{3} \Sigma_{\mathrm{u}}{ }^{+}, v \geq 9\right)+\mathrm{O}_{2}\left(\mathrm{X}^{3} \Sigma_{\mathrm{g}}{ }^{-}, v \geq 1\right) \rightarrow \mathrm{O}_{2}\left(\mathrm{X}^{3} \Sigma_{\mathrm{g}}{ }^{-}\right)+ \\
2 \mathrm{O}\left({ }^{3} \mathrm{P}\right) ; \Delta \mathrm{H}^{0}=-5.7 \mathrm{~kJ} / \mathrm{mol} \\
\mathrm{O}_{2}\left(\mathrm{~B}^{3} \Sigma_{\mathrm{u}}{ }^{-}\right)+\mathrm{O}_{2}\left(\mathrm{X}^{3} \Sigma_{\mathrm{g}}{ }^{-}\right) \rightarrow \mathrm{O}_{2}\left(\mathrm{X}^{3} \Sigma_{\mathrm{g}}{ }^{-}\right)+2 \mathrm{O}\left({ }^{3} \mathrm{P}\right) ; \\
\Delta \mathrm{H}^{0}=-92.1 \mathrm{~kJ} / \mathrm{mol} \\
\mathrm{O}_{2}\left(\mathrm{~B}^{3} \Sigma_{\mathrm{u}}{ }^{-}\right)+\mathrm{O}_{2}\left(\mathrm{X}^{3} \Sigma_{\mathrm{g}}^{-}, v \geq 26\right) \rightarrow \mathrm{O}\left({ }^{1} \mathrm{~S}\right)+\mathrm{O}\left({ }^{3} \mathrm{P}\right)+ \\
\mathrm{O}_{2}\left(\mathrm{X}^{3} \Sigma_{\mathrm{g}}{ }^{-}\right) ; \Delta \mathrm{H}^{0}=-93.3 \mathrm{~kJ} / \mathrm{mol}
\end{gathered}
$$

Reaction (8) contributes to the amount of $\mathrm{O}_{2}\left(\mathrm{~B}^{3} \Sigma_{\mathrm{u}}^{-}\right)$ molecules both in the daytime and in night-time in the MLT layer. The reaction (11) may have importance to the night-time $O\left({ }^{1} S\right)$ budget. Reactions (9) to (11) are important for the stability of oxygen atom concentration during the night.

\subsubsection{Electronically Excited $\mathrm{O}_{2}\left(\beta^{3} \Sigma_{\mathrm{u}}{ }^{+}, \mathrm{a}^{1} \Sigma_{\mathrm{u}}{ }^{+},{ }^{3} \Sigma_{\mathrm{u}}{ }^{+},{ }^{1} \Delta_{\mathrm{u}},{ }^{1} \Pi_{\mathrm{u}}\right.$} and ${ }^{3} \Pi_{\mathrm{u}}$ ):

It is feasible that the collision of these high energy $\mathrm{O}_{2}$ molecules with ozone or $\mathrm{O}_{2}\left(\mathrm{X}^{3} \Sigma_{\mathrm{g}}\right)$ produce $\mathrm{O}\left({ }^{1} \mathrm{~S}\right)$ atoms (reactions 12 and 13).

$$
\begin{array}{r}
\mathrm{O}_{2}\left({ }^{1} \Delta_{\mathrm{u}}\right)+\mathrm{O}_{3} \rightarrow \mathrm{O}\left({ }^{1} \mathrm{~S}\right)+2 \mathrm{O}_{2}\left(\mathrm{X}^{3} \Sigma_{\mathrm{g}}{ }^{-}\right) ; \Delta \mathrm{H}^{0}=-546.3 \mathrm{~kJ} / \mathrm{mol} \\
\mathrm{O}_{2}\left({ }^{1} \Delta_{\mathrm{u}}\right)+\mathrm{O}_{2}\left(\mathrm{X}^{3} \Sigma_{\mathrm{g}}{ }^{-}\right) \rightarrow \mathrm{O}\left({ }^{1} \mathrm{~S}\right)+\mathrm{O}\left({ }^{3} \mathrm{P}\right)+\mathrm{O}_{2}\left(\mathrm{X}^{3} \Sigma_{\mathrm{g}}{ }^{-}\right) ; \\
\Delta \mathrm{H}^{0}=-154.4 \mathrm{~kJ} / \mathrm{mol}
\end{array}
$$




\subsection{Ozone Photolysis and Reactions Thereof}

The ozone molecule is a kind of primus motor in many of the reactions in the MLT layer. Its readiness to react is enhanced by the participation of excited ozone molecules [53]. Wayne [54] has calculated limiting wavelengths for the formation of energetically different combinations of $\mathrm{O}$ $+\mathrm{O}_{2}$ in ozone photolysis (see Table 2).

When ozone is photolyzed by photons of visible light, $\lambda<611 \mathrm{~nm}$, are produced $\mathrm{O}_{2}\left(\mathrm{a}^{1} \Delta_{\mathrm{g}}\right)+\mathrm{O}\left({ }^{3} \mathrm{P}\right)$. With UV photons $\lambda<310 \mathrm{~nm}$, the products are $\mathrm{O}_{2}\left(\mathrm{a}^{1} \Delta_{\mathrm{g}}\right)+\mathrm{O}\left({ }^{1} \mathrm{D}\right)$, and when of $\lambda<266 \mathrm{~nm}$, the products are $\mathrm{O}_{2}\left(\mathrm{~b}^{1} \Sigma_{\mathrm{g}}^{+}\right)+$ $\mathrm{O}\left({ }^{1} \mathrm{D}\right)$. Similarly at $\mathrm{UV}$ wavelengths $\lambda<230 \mathrm{~nm}$ and $\lambda<$ $170 \mathrm{~nm}, \mathrm{O}_{2}\left(\mathrm{~A}^{3} \Sigma_{\mathrm{u}}^{+}\right)+\mathrm{O}\left({ }^{3} \mathrm{P}\right)$ and $\mathrm{O}_{2}\left(\mathrm{~B}^{3} \Sigma_{\mathrm{g}}{ }^{-}\right)+\mathrm{O}\left({ }^{3} \mathrm{P}\right)$ are formed, respectively. When these excited molecules are dissociated by UV photons $\lambda<242 \mathrm{~nm}$ two $\mathrm{O}$ atoms are formed. The net effect is the production of three $\mathrm{O}$ atoms from one ozone molecule.

Table 2. Long wavelength limits ( $\mathrm{nm}$ ) for the production of various electronic states of $\mathrm{O}_{2}$ and $\mathrm{O}$ in the primary step of ozone photolysis [54]

\begin{tabular}{|c|c|c|c|c|c|}
\hline \multirow{2}{*}{$\mathrm{O}$ atom } & \multicolumn{5}{|c|}{ Electronic state of $\mathrm{O}_{2}$ molecules } \\
\cline { 2 - 6 } & $\mathrm{X}^{3} \Sigma_{\mathrm{g}}{ }^{-}$ & $\mathrm{a}^{1} \Delta_{\mathrm{g}}$ & $\mathrm{b}^{1} \Sigma_{\mathrm{g}}{ }^{+}$ & $\mathrm{A}^{3} \Sigma_{\mathrm{u}}{ }^{+}$ & $\mathrm{B}^{3} \Sigma_{\mathrm{u}}{ }^{-}$ \\
\hline${ }^{3} \mathrm{P}$ & 1180 & 611 & 463 & 230 & 170 \\
\hline${ }^{1} \mathrm{D}$ & 411 & 310 & 266 & 167 & 150 \\
\hline${ }^{1} \mathrm{~S}$ & 234 & 196 & 179 & 129 & 108 \\
\hline
\end{tabular}

Tu and Nee [26] suggested that when a UV photon at the wavelength $\lambda=121.6 \mathrm{~nm}$ dissociates ozone, the result is direct formation of three oxygen atoms from one ozone molecule:

$$
\begin{gathered}
\mathrm{O}_{3}+\mathrm{h} v(\lambda=121.6 \mathrm{~nm}) \rightarrow \mathrm{O}_{2} *+\mathrm{O} \\
\mathrm{O}_{2} *+\mathrm{O} \rightarrow \mathrm{O}+\mathrm{O}+\mathrm{O}
\end{gathered}
$$

The $\Delta \mathrm{H}^{0}$ of the starting products (ozone and energy of UV photon) of the reaction (14) is $142.7 \mathrm{~kJ} / \mathrm{mol}+983.8$ $\mathrm{kJ} / \mathrm{mol}=1126.5 \mathrm{~kJ} / \mathrm{mol}$. When the $\mathrm{O}$ atom is $\mathrm{O}\left({ }^{3} \mathrm{P}\right)$, then the energy content of the $\mathrm{O}_{2}{ }^{*}$ molecule is $877.3 \mathrm{~kJ} / \mathrm{mol}$. It exceeds the dissociation energy of $\left.\mathrm{O}_{2} \mathrm{~B}^{3} \Sigma_{\mathrm{u}}{ }^{-}\right)(682.6 \mathrm{~kJ} / \mathrm{mol})$ and do not reach the formation enthalpy of $\mathrm{O}_{2}\left(\beta^{3} \Sigma_{\mathrm{u}}^{+}\right)$ $(902.2 \mathrm{~kJ} / \mathrm{mol})$. At the wavelength of $\lambda=118.7 \mathrm{~nm}$ the energy content of the $\mathrm{O}_{2} *$ is $901.3 \mathrm{~kJ} / \mathrm{mol}$ which is just below the formation enthalpy of $\mathrm{O}_{2} \beta^{3} \Sigma_{\mathrm{u}}^{+}$). So between the wavelengths of 118.6 to $121.6 \mathrm{~nm}$ there is a window in which three oxygen atoms are formed from one ozone molecule.

\subsection{Reactions of $\mathrm{O}\left({ }^{1} \mathrm{D}\right)$ with $\mathrm{O}_{3}$ and $\mathrm{O}_{2}\left(\mathrm{X}^{3} \Sigma_{\mathrm{g}}{ }^{-}\right)$}

In the reaction $\mathrm{O}\left({ }^{1} \mathrm{D}\right)+\mathrm{O}_{3}$ is formed two $\mathrm{O}_{2}$ molecules. At least one of these $\mathrm{O}_{2}$ molecules produced is excited (reaction 16). This excited $\mathrm{O}_{2}$ molecule is capable of decomposing additional $\mathrm{O}_{3}$, yielding another $\mathrm{O}\left({ }^{1} \mathrm{D}\right)$ atom (reaction 17) [55, 56]:

$\mathrm{O}\left({ }^{1} \mathrm{D}\right)+\mathrm{O}_{3} \rightarrow \mathrm{O}_{2}\left(\mathrm{~A}^{3} \Sigma_{\mathrm{u}}^{+}\right)+\mathrm{O}_{2}\left(\mathrm{X}^{3} \Sigma_{\mathrm{g}}^{-}\right) ; \Delta \mathrm{H}^{0}=-62.8 \mathrm{~kJ} / \mathrm{mol}$

$$
\begin{gathered}
\mathrm{O}_{2}\left(\mathrm{~A}^{3} \Sigma_{\mathrm{u}}{ }^{+}\right)+\mathrm{O}_{3} \rightarrow \mathrm{O}\left({ }^{1} \mathrm{D}\right)+2 \mathrm{O}_{2}\left(\mathrm{X}^{3} \Sigma_{\mathrm{g}}^{-}\right) ; \\
\Delta \mathrm{H}^{0}=-122.6 \mathrm{~kJ} / \mathrm{mol}
\end{gathered}
$$

Reactions (16) and (17) constitute a chain reaction with reported chain lengths as large as 16 [55]. This allows $O\left({ }^{1} \mathrm{D}\right)$ to fuel the dynamics during the night. The reaction (16) is an important night-time source of $\mathrm{O}_{2}\left(\mathrm{~A}^{3} \Sigma_{\mathrm{u}}^{+}\right)$as well. It is $162.8 \mathrm{~kJ} / \mathrm{mol}$ exothermic, so one mole of $\mathrm{O}_{2}\left(\mathrm{a}^{1} \Delta_{\mathrm{g}}\right)$ or $\mathrm{O}_{2}\left(\mathrm{~b}^{1} \Sigma_{\mathrm{g}}^{+}\right)$could also be produced.

The three-body reaction (18) produces excited $\mathrm{O}_{2}\left(\mathrm{~b}^{1} \Sigma_{\mathrm{g}}{ }^{+}\right)$ molecules and $\mathrm{O}\left({ }^{3} \mathrm{P}\right)$ atoms. The energy transfer via $\mathrm{O}\left({ }^{1} \mathrm{D}\right)$ to $\mathrm{O}_{2}$ is an important source of $\mathrm{O}_{2}\left(\mathrm{~b}^{1} \Sigma_{\mathrm{g}}^{+}\right)$at vibrational levels $v=0$ and 1 in Earth's atmosphere [57].

$$
\begin{gathered}
\mathrm{O}\left({ }^{1} \mathrm{D}\right)+\mathrm{O}_{2}\left(\mathrm{X}^{3} \Sigma_{\mathrm{g}}{ }^{-}\right)+\mathrm{M} \rightarrow \mathrm{O}_{2}\left(\mathrm{~b}^{1} \Sigma_{\mathrm{g}}^{+}\right)+\mathrm{O}\left({ }^{3} \mathrm{P}\right)+\mathrm{M} ; \\
\Delta \mathrm{H}^{0}=-32.7 \mathrm{~kJ} / \mathrm{mol}
\end{gathered}
$$

\subsection{Formation of $O\left({ }^{1} S\right)$ Atom}

In the photolysis of ozone UV photons at wavelengths $230<\lambda<234 \mathrm{~nm}$ produce $\mathrm{O}\left({ }^{1} \mathrm{~S}\right)$ and $\mathrm{O}_{2}\left(\mathrm{X}^{3} \Sigma_{\mathrm{g}}{ }^{-}\right.$) (see Table 2). This reaction is feasible at night as well.

Krasnopolsky and Levfévre [58] suggest that reaction (19) would be important in producing $\mathrm{O}\left({ }^{1} \mathrm{~S}\right)$.

$$
\begin{gathered}
\mathrm{O}\left({ }^{3} \mathrm{P}\right)+\mathrm{O}_{2}\left(\mathrm{~A}^{3} \Sigma_{\mathrm{u}}^{+}, v \geq 6\right) \rightarrow \mathrm{O}\left({ }^{1} \mathrm{~S}\right)+\mathrm{O}_{2}\left(\mathrm{X}^{3} \Sigma_{\mathrm{g}}{ }^{-}\right) ; \\
\Delta \mathrm{H}^{0}=-64.4 \mathrm{~kJ} / \mathrm{mol}
\end{gathered}
$$

Considering the higher energy, even the $\mathrm{O}_{2}\left(\mathrm{~B}^{3} \Sigma_{\mathrm{u}}{ }^{-}, v=\right.$ 0 ), would enter the same reaction, and produce a vibrationally excited ground state $\mathrm{O}_{2}$ molecule as well (reaction 20).

$$
\begin{gathered}
\mathrm{O}\left({ }^{3} \mathrm{P}\right)+\mathrm{O}_{2}\left(\mathrm{~B}^{3} \Sigma_{\mathrm{u}}^{-}\right) \rightarrow \mathrm{O}\left({ }^{1} \mathrm{~S}\right)+\mathrm{O}_{2}\left(\mathrm{X}^{3} \Sigma_{\mathrm{g}}^{-}, v \leq 6\right) ; \\
\Delta \mathrm{H}^{0}=-79.2 \mathrm{~kJ} / \mathrm{mol}
\end{gathered}
$$

The highly excited molecules $\mathrm{O}_{2}\left({ }^{3} \Sigma_{\mathrm{u}}+{ }^{1} \Delta_{\mathrm{u}},{ }^{1} \Pi_{\mathrm{u}}\right.$ and $\left.{ }^{3} \Pi_{\mathrm{u}}\right)$ contain so much energy that their reaction with $\mathrm{O}\left({ }^{3} \mathrm{P}\right)$ atoms would produce $\mathrm{O}\left({ }^{1} \mathrm{~S}\right)$ and $\mathrm{O}_{2}\left(\mathrm{~B}^{3} \Sigma_{\mathrm{u}}^{-}, v>5\right)$.

$$
\begin{gathered}
\mathrm{O}\left({ }^{3} \mathrm{P}\right)+\mathrm{O}_{2}\left({ }^{3} \Sigma_{\mathrm{u}}^{+}\right) \rightarrow \mathrm{O}\left({ }^{1} \mathrm{~S}\right)+\mathrm{O}_{2}\left(\mathrm{~B}^{3} \Sigma_{\mathrm{u}}^{-}, v>5\right) ; \\
\Delta \mathrm{H}^{0}=-12.6 \mathrm{~kJ} / \mathrm{mol}
\end{gathered}
$$

By reacting with $\mathrm{O}\left({ }^{3} \mathrm{P}\right)$, the $\mathrm{O}_{2}\left(\mathrm{~B}^{3} \Sigma_{\mathrm{u}}^{-}, v>5\right)$ would produce $\mathrm{O}\left({ }^{1} \mathrm{~S}\right)$ and $\mathrm{O}_{2}\left(\mathrm{X}^{3} \Sigma_{\mathrm{g}}^{-}, v \leq 9\right)$ (see reaction 20$)$. This cascading process (reactions 20 and 21) emphasizes the importance of highly excited neutral $\mathrm{O}_{2}$ molecules in producing $\mathrm{O}\left({ }^{1} \mathrm{~S}\right)$ and $\mathrm{O}_{2}\left(\mathrm{~B}^{3} \Sigma_{u}{ }^{-}\right)$especially during the night-time in the MLT layer.

\subsection{Nightglows as Evidences of the Night-time Dynamics of $\mathrm{O}$ and $\mathrm{O}_{2}$ Species in the MLT Layer}

Nightglows are the emission of UV, visible or IR light by excited atoms and molecules when they are relaxing to the lower excited states or ground states in the upper atmosphere. Nightglows in the MLT layer last throughout the night with only a little falling off [59]. Understanding the nightglow dynamics is vital to understanding the dynamics of oxygen species during the night in the secondary ozone zone. 


\subsubsection{IR and Visible Nightglows}

These nightglows are due to the relaxing of excited molecules $\mathrm{O}_{2}\left(\mathrm{a}^{1} \Delta_{\mathrm{g}}\right.$ and $\left.\mathrm{b}^{1} \Sigma_{\mathrm{g}}{ }^{+}\right)$. The transitions $\mathrm{O}_{2}\left(\mathrm{a}^{1} \Delta_{\mathrm{g}}, \mathrm{v}=0\right.$, $1) \rightarrow \mathrm{O}_{2}\left(\mathrm{X}^{3} \Sigma_{\mathrm{g}}{ }^{-}\right)$are called the IR atmospheric system. IR photons are emitted at wavelengths at $1060 \mathrm{~nm})$ and 1269 $\mathrm{nm}$. The transition $\mathrm{O}_{2}\left(\mathrm{~b}^{1} \Sigma_{\mathrm{g}}{ }^{+}, v=0\right.$ and 1$) \rightarrow \mathrm{O}_{2}\left(\mathrm{X}^{3} \Sigma_{\mathrm{g}}{ }^{-}\right)$is called the Atmospheric system. The emitting wavelengths are $761.9 \mathrm{~nm}$ and $864.5 \mathrm{~nm}$ [60].

\subsubsection{Nightglows Due to the Oxygen Green Line and Red Line Emissions}

The green nightglow of the $\mathrm{O}\left({ }^{1} \mathrm{~S} \rightarrow{ }^{1} \mathrm{D}\right)$ transition is at a wavelength of $557.7 \mathrm{~nm}$ and is located at two elevations. The first peaks at an altitude between 300 and $160 \mathrm{~km}$ in the thermosphere [61] and the second one in the MLT layer at an altitude of $94 \mathrm{~km}$ [62].

The transition of $\mathrm{O}\left({ }^{1} \mathrm{D}\right) \rightarrow \mathrm{O}\left({ }^{3} \mathrm{P}\right)$ produces the red nightglow at $630 \mathrm{~nm}$ and at $636.4 \mathrm{~nm}$ at an altitude of 300 to $160 \mathrm{~km}$. Its intensity is $1000 \mathrm{R}$ at the close of the day but diminishes to $50 \mathrm{R}$ by midnight [61]. The green line nightglow at the $170 \mathrm{~km}$ diminishes soon after sunset from $1000 \mathrm{R}$ to $300 \mathrm{R}$ and by the midnight much more [63]. (1 rayleigh equals $10^{8}$ photons per $\mathrm{cm}^{2}$ column per second [61]).

In the altitude range of 300 to $160 \mathrm{~km}$ the most important sources of $\mathrm{O}\left({ }^{1} \mathrm{~S}\right)$ are $\mathrm{O}_{2}^{+}$ions are generated during the daytime, and are then exhausted by midnight by electrons and $\mathrm{N}$ atoms. The formation of $\mathrm{O}_{2}{ }^{+}$ions by the EUV from geocorona, the formation of $\mathrm{O}\left({ }^{1} \mathrm{~S}\right)$ by the three-body reaction of $\mathrm{O}+\mathrm{O}+\mathrm{O}$ atoms and the contribution from the galactic background [63] continues to provide so much $\mathrm{O}\left({ }^{1} \mathrm{~S}\right)$ that the falling-off stops at the $50 \mathrm{R}$ level.

In the MLT layer $\mathrm{O}\left({ }^{1} \mathrm{~S}\right)$ is steadily formed throughout the night, so the intensity of the green line nightglow emission stays at $337 \mathrm{R}$ [64].

\subsubsection{Ultraviolet Nightglows}

Figure 4 presents the entire UV nightglow radiation of Earth [65]. It is generated

(1) by $\mathrm{H}$ atoms (102.6 and $121.6 \mathrm{~nm}$ [66] and by $\mathrm{O}$ atoms from geocorona

(2) from relaxation of excited NO molecules, the wavelengths of $\delta$ band are 190-240 nm and those of the $\gamma$ band are 225-270 $\mathrm{nm}$.

(3) via Herzberg systems [39]:

-Herzberg I system $\mathrm{O}_{2}\left(\mathrm{~A}^{3} \Sigma_{\mathrm{u}}{ }^{+} \rightarrow \mathrm{X}^{3} \Sigma_{\mathrm{g}}{ }^{-}\right)$, emitting wavelengths are $243-488 \mathrm{~nm}$.

-Herzberg II system $\mathrm{O}_{2}\left(\mathrm{c}^{1} \Sigma_{\mathrm{u}}{ }^{-} \rightarrow \mathrm{X}^{3} \Sigma_{\mathrm{g}}{ }^{-}\right)$, emitting wavelengths are 254-271.5 nm and 449-479 nm

-Herzberg III system $\mathrm{O}_{2}\left(\mathrm{~A}^{, 3} \Delta_{\mathrm{u}} \rightarrow \mathrm{X}^{3} \Sigma_{\mathrm{g}}{ }^{-}\right)$, emitting wavelengths are $257-263 \mathrm{~nm}$.

(4) via Chamberlain system $\mathrm{O}_{2}\left(\mathrm{~A}^{3} \Delta_{\mathrm{u}} \rightarrow \mathrm{a}^{1} \Delta_{\mathrm{g}}\right)$, emitting wavelengths are 370-438 $\mathrm{nm}$ [39].

(5) via the Schumann-Runge system $\mathrm{O}_{2}\left(\mathrm{~B}^{3} \Sigma_{\mathrm{u}}{ }^{-} \rightarrow \mathrm{X}^{3} \Sigma_{\mathrm{g}}{ }^{-}\right)$, emitting wavelengths are 211-566 nm [39, 45].
(6) via oxygen atom UV nightglow $\mathrm{O}\left({ }^{1} \mathrm{~S} \rightarrow{ }^{3} \mathrm{P}\right)$, emitting wavelength is $297.2 \mathrm{~nm}$ [64].

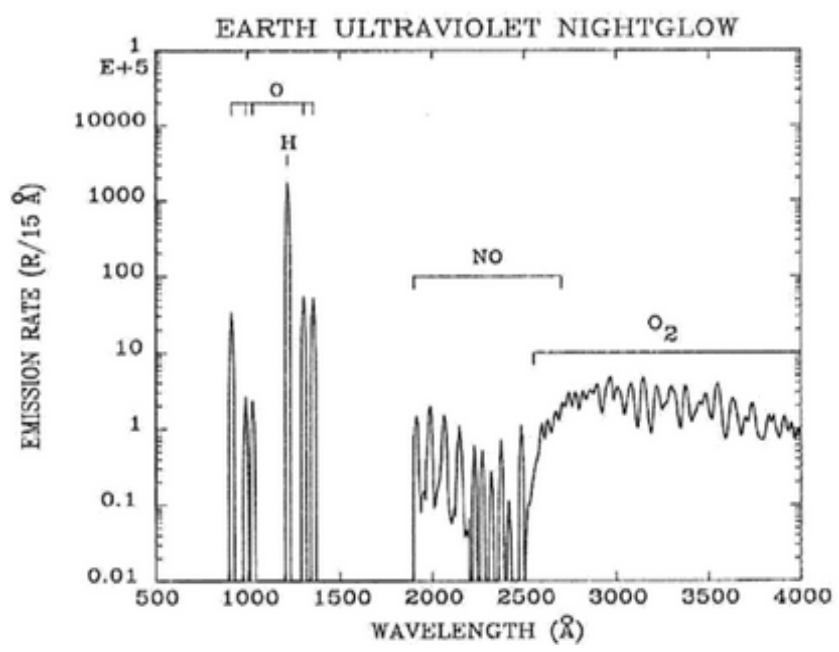

Figure 4. The entire composite UV nightglow [65]

Nightglows have been found on Venus as well $[67,68]$. The UV nightglows due to $\mathrm{O}_{2}\left(\mathrm{c}^{1} \Sigma^{-} \mathrm{u} \rightarrow \mathrm{X}^{3} \Sigma_{\mathrm{g}}{ }^{-}\right)$and $\mathrm{O}_{2}\left(\mathrm{~A}^{, 3} \Delta_{\mathrm{u}} \rightarrow \mathrm{a}^{1} \Delta_{\mathrm{g}}\right)$ emissions have a greater intensity in rayleighs on Venus than they do on Earth [68]. The ozone layer on Venus at 100 kilometres above the planet's surface is considerably less dense compared to the MLT ozone layer at night [69].

So a likely conclusion is that on Earth during the night, the MLT ozone layer absorbs part of the UV photons emitted during nightglow. This absorbed UV radiation may have an important auxiliary role in the night-time dynamics of excited oxygen molecules and ozone.

\subsubsection{Nightglow Dynamics: Economic Use of Available Energy}

Energy reserved in the MLT layer during the daytime in the excited $\mathrm{O}_{2}$ molecules and their replenishment by diffusion from above may not be enough to allow the nightglows to run throughout the night with steady intensity. Additional energy is provided by EUV from geocorona (producing highly excited $\mathrm{O}_{2}$ molecules), UV from the nightglows of $\mathrm{NO} \delta$ (producing $\mathrm{O}_{2}\left(\mathrm{~B}^{3} \Sigma_{\mathrm{u}}{ }^{-}\right.$) and NO $\gamma$ bands (producing $\mathrm{O}_{2}\left(\mathrm{~A}^{3} \Sigma_{\mathrm{u}}^{+}\right)$, and UV generated by the nightglows of $\mathrm{O}_{2}\left(\mathrm{~A}^{3} \Sigma_{\mathrm{u}}{ }^{+}, \mathrm{c}^{1} \Sigma_{\mathrm{u}}^{-}\right.$and $\left.\mathrm{A}^{, 3} \Delta_{\mathrm{u}}\right)$ molecules (causing photolysis of ozone).

Visible photons from the oxygen green line produce $\mathrm{O}_{2}$ $\left(\mathrm{a}^{1} \Delta_{\mathrm{g}}\right)$ via the photolysis of ozone Quenching of $\mathrm{O}\left({ }^{1} \mathrm{~S}\right)$ provides $\mathrm{O}\left({ }^{1} \mathrm{D}\right)$ which reactions with ozone produce $\mathrm{O}_{2}\left(\mathrm{~A}^{3} \Sigma_{\mathrm{u}}{ }^{+}, \mathrm{c}^{1} \Sigma_{\mathrm{u}}{ }^{-}\right.$and $\left.\mathrm{A}^{3} \Delta_{\mathrm{u}}\right)$ molecules.

In the MLT ozone layer the use of energy is highly efficient. Energy-rich compounds are upgraded from "waste" energy, and with no cost to the "middle man of ozone", as these reactions provide also $\mathrm{O}$ atoms, which produce ozone. 


\section{Conclusions}

During the daytime in the MLT layer the EUV photons (102.8 to $124 \mathrm{~nm}$ ) are photoexcitating $\mathrm{O}_{2}$ molecules up to $11.07 \mathrm{eV}$ level. $\mathrm{O}_{2}\left(\mathrm{~B}^{3} \Sigma_{\mathrm{u}}{ }^{-}, v=0-19\right)$ molecules are formed via photoexcitation in the Schumann-Runge bands.

Dissociation of $\mathrm{O}_{2}$ molecules in the Schumann-Runge and Herzberg continuums produces $\mathrm{O}$ atoms. In the photolysis of ozone there is a window between the wavelengths of 118.7 to $121.6 \mathrm{~nm}$ in which three oxygen atoms are formed from one ozone molecule. Vibrationally excited $\mathrm{O}_{2}\left(\mathrm{X}^{3} \Sigma_{\mathrm{g}}^{-}, v \geq 26\right)$ molecules are formed via ozone photolysis., Both $\mathrm{O}_{2}\left(\mathrm{~B}^{3} \Sigma_{\mathrm{u}}{ }^{-}\right)$and $\left(\mathrm{O}_{2}\left(\mathrm{X}^{3} \Sigma_{\mathrm{g}}^{-}, v \geq 26\right)\right.$ are able to react with $\mathrm{O}_{2}\left(\mathrm{X}^{3} \Sigma_{\mathrm{g}}^{-}, v=0\right)$ to produce $\mathrm{O}$ and $\mathrm{O}_{3}$. The $\mathrm{O}$ atom concentration reaches its atmospheric maximum in the MLT layer.

Due to the abundance of $\mathrm{O}$ atoms, a small but significant ozone concentration (as compared to the regions above or immediately below) remains during the daytime, even though ozone is then rapidly destroyed by photolysis.

During the night, solar UV radiation is radically reduced. Ozone, being the "weak" oxygen species, gains the most. The number of $\mathrm{O}$ atoms shows no diurnal variation in the MLT layer. This leads to a ten-fold increase of ozone concentration over the course of the night.

The MLT ozone zone coincides with the ionospheric D-ring, so there is a small concentration of electrons at night as well.

At an altitude of $110 \mathrm{~km}, \mathrm{O}_{2}{ }^{+}$ions enter the MLT layer via diffusion. Highly energetic neutral oxygen molecules (9.35 to $11.07 \mathrm{eV}$ ) generated during the daytime in the MLT layer are also replenished by diffusion from above. $\mathrm{O}\left({ }^{1} \mathrm{~S}\right)$ atoms are produced via the $\mathrm{DR}$ reaction, via reactions of excited oxygen molecules $\left(E_{\mathrm{el}} \geq 9.35 \mathrm{eV}\right)$ with $\mathrm{O}_{2}, \mathrm{O}_{3}$ or $\mathrm{O}$, and via reaction of $\mathrm{O}_{2}\left(\mathrm{~B}^{3} \Sigma_{\mathrm{u}}{ }^{-}\right)+\mathrm{O}\left({ }^{3} \mathrm{P}\right)$ These reactions produce enough $\mathrm{O}\left({ }^{1} \mathrm{~S}\right)$ atoms to keep the green line nightglow in the MLT layer running at a rather steady state throughout the night.

$\mathrm{O}\left({ }^{1} \mathrm{D}\right)$ quenched from $\mathrm{O}\left({ }^{1} \mathrm{~S}\right)$, and produced in collision reactions of excited oxygen molecules and ozone is important for keeping the overall $\mathrm{O}$ atom concentration at a highly reactive level during the night as well.

\section{REFERENCES}

[1] L. Thomas and M. R. Bowman. The diurnal variations of hydrogen and oxygen constituents in the mesosphere and lower thermosphere, Journal of Atmospheric and Terrestrial Physics, Vol. 34, No. 11, 1843-1858, 1972. DOI: 10.016/0021-9169(72)90061-X

[2] P. B. Hays and R. G. Roble, Observation of mesospheric ozone at low latitudes, Planetary and Space Science, Vol. 21, Issue 2, 273-279, 1973.

http://dx.doi.org/10.1016/0032-0633(73)90011-1

[3] D. E. Miller and P. Ryder. Measurement of the ozone concentration from 55 to $95 \mathrm{~km}$ at sunset, Planetary and Space Science, Vol. 21, Issue 6, 963-970, 1973. DOI: 0.1016/0032-0633(73)90142-6

[4] E. Kyrölä. GOMOS/ENVISAT overview. Day 2, Lecture 5, Basic Instruments. In: Dragon Advanced Training Course in Atmospheric Remote Sensing, Beijing, p. 2 and 13, 2006. Available online:

https://earth.esa.int/dragon/D2_L5_Kyrola.pdf

[5] E., J. Kyrölä, Tamminen, G. W. Leppelmeier, V. Sofieva, S. Hassinen, A. Seppälä, P. T. Verronen. J. L. Bertaux, A. Hauchecorne, F. Dalaudier, D. Fussen, F. Vanhellemont, O. Fanton d'Andon, G. Barrot, A. Mangin, B. Theodore, M. Guirlet, R. Koopman, L. Saavedra, P. Snoeij, T. Fehr. Nighttime ozone profiles in the stratosphere and mesosphere by Global Ozone Monitoring by Occultation of Stars on Envisat, Journal of Geophysical Research, Vol. 111, D24306, 2006. DOI: 10.1029/2006JD007193

[6] E. Kyrölä and The GOMOS Team. GOMOS measurements in 2002-2007, 1st International HEPPA Workshop 2008. Book of Abstracts, Finnish Meteorological Institute, Reports, P. T. Verronen Ed., 2, 72-73, 2008.

[7] A. K. Smith and D. R. Marsh. Processes that account for the ozone maximum at the mesopause, Journal of Geophysical Research, Vol. 110, D23305, 2005. DOI: 10.1029/2005JD006298

[8] A. E. E. Rogers, M. Lekberg, P. Pratap. Seasonal and Diurnal Variations of Ozone near the Mesopause from Observations of the $11.072-\mathrm{GHz}$ Line, Journal of Atmospheric and Oceanic Technology, Vol. 26, 2192-2199, 2009. http://dx.doi.org/10.1175/2009jtecha1291.1

[9] H. S. W Massey. Atomic Collisions and the Lower Ionosphere at Midlatitudes. In: Applied Atomic Collision Physics. Vol. 1. Atmospheric Physics and Chemistry, Academic Press, New York, p. 107, 1982.

[10] G. W. vanLoon and S. J. Duffy, Environmental Chemistry A Global Perspective, Oxford University Press, 49-50, 2005. DOI: 10.1016/0021-9169(72)90061-X

[11] B. J. Finlayson-Pitts and J. R. Pitts Jr. Chemistry of the Upper and Lower Atmosphere, Academic Press, p. 54 and p. 943, 2000.

[12] F. J. Lin, K. V. Chance, and W. A. Traub. Atomic Oxygen in the Lower Thermosphere, Journal of Geophysical Research, Vol. 92, No. D4, 4325-4336, 1987. DOI: 10.1029/JD092iD04p04325

[13] J. Hedin, J. Gumbel, J. Stegman and G. Witt. Use of $\mathrm{O}_{2}$ airglow for calibrating direct atomic oxygen measurements from sounding rockets, Atmospheric Measuring Techniques, Vol. 2, 801-812, 2009.

www.atmos-meas-tech.net/2/801/2009/

[14] T. M. Donahue, T. Parkinson, E. C. Zipf, J. P. Doering, W. G. Fastie, and R. E. Miller. Excitation of the auroral green line by dissociative recombination of the oxygen molecular ion: Analysis of two rocket experiments. Planetary and Space Science, Vol. 16, 737 - 747 (1968).

[15] H. S. W Massey. The Photochemistry of the Midlatitude Ionosphere. In: Applied Atomic Collision Physics, Volume 1: Atmospheric Physics and Chemistry, Academic Press, New York, 1982, p. 32. 
[16] T. G. Slanger and R. C. Copeland. Energetic Oxygen in the Upper Atmosphere and the Laboratory, Chemical Reviews, Vol. 103, No. 12, 4731-4766, 2003. DOI: 10.1021/cr0205311

[17] R. E. Huffman. Absorption cross-sections of atmospheric gases for use of in aeronomy. Canadian Journal of Chemistry, Vol. 47, 1823-1834, 1969.

[18] K. Watanabe, M. Zelikoff and E. C. Y. Inn. Absorption Coefficients of several Atmospheric Gases, Geophysical Research Directorate, Air Force Cambridge Research Center, Cambridge, Massaschusetts, Geophysical Research Papers 21, 1-79, 1953

[19] H. S. W. Massey. Atomic Collisions and the Lower Ionosphere at Midlatitudes. In: Applied Atomic Collision Physics. Vol. 1, Atmospheric Physics and Chemistry, Academic Press, New York, 115-116, 1982.

[20] R. E. Huffman, Y. Tanaka and J. C. Larrabee: Nitrogen and oxygen absorption cross-sections in the vacuum ultra-violet, Discussions of the Faraday Society, Vol. 37, 159-166, 1964. DOI: http://dx.doi.org/10.1039/DF9643700159

[21] J. L. Lean. Calculations of Lyman Alpha Absorption in the Mesosphere, Atmospheric Ozone, Proceedings of the Quadrennial Ozone Symposium held in Halkidiki, Greece 37 September 1984, D. Reidel Publishing Company, Dodrecht, 697-701, 1985. DOI: 10.1007/978-94-009-5313-0

[22] R. A. Copeland, K. Knutsen and T. G. Slanger. Using Laser-Induced Fluorescence to Study molecules of Atmospheric importance. In: The Proceedings of the International Conference on Lasers '93- Lake Tahoe, NV, December 6-9, 1993. 318-325, 1993.

[23] M. A. Box and G. P. Box. Physics of Radiation and Climate, CRC Press, Taylor \& Francis Group, 295-296, 2016.

[24] D. A. Newnham and J. Ballard. Visible absorption cross-sections and integrated absorption intensities of molecular oxygen $\left(\mathrm{O}_{2}\right.$ and $\left.\mathrm{O}_{4}\right)$, Journal of Geophysical Research, Vol. 103, No. D22, 28,801-28,816, 1998.

[25] K. M. Smith and D.A. Newnham. Near-infrared absorption cross-sections and integrated absorption intensities of molecular oxygen $\left(\mathrm{O}_{2}, \mathrm{O}_{2}-\mathrm{O}_{2}\right.$, and $\left.\mathrm{O}_{2}-\mathrm{N}_{2}\right)$, Journal of Geophysical Research, Vol. 105, 7383-7396, 2000.

[26] S. J. Tu and J. B. Nee, Absorption spectrum of ozone in the 105-200 nm wavelength region, Surface Review and Letters, Vol. 9, No. 1, 125-128, 2002.

[27] V. Gorshelev, A. Serdyuchenko, M. Weber, W. Chehade, and J. P. Burrows. High spectral resolution ozone absorption cross-sections - Part 1: Measurements, data analysis and comparison with previous measurements around $293 \mathrm{~K}$, Atmospheric Measuring Techniques, Vol. 7, 609-624, 2014. DOI: 10.5194/amt-7-609-2014.

[28] A. Calo. Electron Spectroscopy of Atoms and Molecules using Synchrotron Radiation, UV Radiation and Electron Impact, Report Series in Physical Sciences. Report No. 47. University of Oulu, 2007.

[29] F. L. Pilar. Elementary Quantum Chemistry, Dover Publications, New York, p. 225 and p. 335, 1990.

[30] M. H. Alexander: Molecular Electronic Structure, Available online:

http://www2.chem.umd.edu/groups/alexander/chem691/Ch ap3.pdf

[31] E. Wigner, Ueber die Erhaltungssätze in der Quantenmechanik. Nachrichten von der Gesellschaft der Wissenschaften zu Göttingen, Mathematisch-Physikalische Zeitschriftenband, Vol. I, Part II, 375-381, 1972.

[32] C. Carbagno, J. Behler, A. Gross and K. Reuter, Fingerprints for Spin-Selection Rules in the Interaction Dynamics of $\mathrm{O}_{2}$ at $\mathrm{Al}(111)$, Physical Review Letters, Vol. 101, 096104-1096104-4, 2008. DOI: 10.1103/PhysRevLett.101.096104

[33] Available online: http://growyouthful.com/tips/vitamin-d-and-sunlight.php

[34] J. Shi and J. Baker. Emission from ozone excited electronic states, The Journal of Physical Chemistry, Vol. 94, Issue 22, 8390-8393, 1990. DOI: 10.1021/j100385a004

[35] Available online: https://en.wikipedia.org/wiki/Morse_potential

[36] T. Carrington and D. Garvin. The Chemical production of Excited States. In: Comprehensive Chemical Kinetics Vol. 3, The Formation and Decay of Excited States, Elsevier Amsterdam, p. 126, 1969.

[37] T. G. Slanger and P. C. Cosby. $\mathrm{O}_{2}$ Spectroscopy below 5.1 eV, The Journal of Physical Chemistry, Vol. 92, No. 2, 267282, 1988. DOI: 10.1021/j100313a008

[38]B. R. Lewis and S. T. Gibson. Rotational line strengths in ${ }^{3} \Sigma^{+}-{ }^{3} \Sigma^{-}$electronic transitions. The $\beta^{3} \Sigma_{\mathrm{u}}^{+}-X^{3} \Sigma_{\mathrm{g}}^{-}$and $A^{3} \Sigma_{\mathrm{u}}{ }^{+}-$ $X^{3} \Sigma_{\mathrm{g}}{ }^{-}$systems of molecular oxygen, Canadian Journal of Physics, Vol. 68, No. 2, 231-237, 1990. DOI: https://doi.org/10.1139/p90-034

[39] P. H. Krupenie. The Spectrum of Molecular Oxygen, Journal of Physical Chemistry Reference Data, Vol. 1, No. 2, 423 534, 1972.

[40] P. D. Cooper, R. E. Johnson and T. I. Quickenden. A review of possible optical absorption features of oxygen molecules in the icy surfaces of outer solar system bodies, Planetary and Space Science Vol. 51, 183-192, 2003. DOI: 10.1016/S0032-0633(02)00205-2

[41] K. M. Smith and D. A. Newnham. Near-infrared absorption spectroscopy of oxygen and nitrogen gas mixtures, Chemical Physical Letters, Vol. 308, Issues 1-2, 1-6, 1999.

[42]T. G. Slanger. Generation of $\mathrm{O}_{2}\left(\mathrm{C}^{1} \Sigma_{\mathrm{u}}^{-}, \mathrm{C}^{3} \Delta_{\mathrm{u}}, \mathrm{A}_{3} \Sigma_{\mathrm{u}}^{+}\right)$from oxygen atom recombination, The Journal of Chemical Physics 69, Issue 11, 4779-4791, 1978. DOI: http://dx.doi.org/10.1063/1.436504

[43] C. S. Burton and W. A. Noyes, Jr. Effect of Low Energy Radiation. In: Comprehensive Chemical Kinetics, Vol. 3, The Formation and Decay of Excited States, Elsevier Amsterdam, p. 26, 1969.

[44] P. J. Flory. Predissociation of the Oxygen Molecule, The Journal of Chemical Physics, Volume 4, Issue 1, p. 23-27, 1936.

[45] K. Yoshino, D. E. Freeman and W. H. Parkinson. Atlas of the Schuman-Runge Absorption Bands of $\mathrm{O}_{2}$ in the Wavelength Region 175-205 nm, Journal of Physical and 
Chemical Reference Data, Vol. 13, Issue 1, 207-227, 1984. DOI: $10.1063 / 1.555702$

[46] V. Sick, M. Decker, J. Heinze and W Stricker. Collisional processes in the $\mathrm{O}_{2} \mathrm{~B}^{3} \Sigma_{\mathrm{u}}-$ state, Chemical Physics Letters, Vol. 249, Issue 5-6, 335-340, 1996.

[47] J. P. England, B. R. Lewis and S. T. Bihson. Assignment of the ${ }^{3} \Pi_{u} \leftarrow X^{3} \Sigma^{-}{ }_{g}$ bands of $\mathrm{O}_{2}$ observed in the region 1040 $1200 \AA$ A , The Journal of Chemical Physics Vol. 104, Issue 8, 2765-2772. Issue $8, \quad 1996 . \quad$ DOI: http://dx.doi.org/10.1063/1.471099

[48] L. B. Loeb. The Energy of Formation of Negative Ions in $\mathrm{O}_{2}$, Physical Review, Vol. 48, 684-689, 1935.

[49] E. C Zipf. The OI $\left({ }^{1} \mathrm{~S}\right)$ state: Its quenching by $\mathrm{O}_{2}$ and formation by the dissociative recombination of vibrational excited $\mathrm{O}_{2}{ }^{+}$ions, Geophysical Research Letters, Vol. 6, No. 10, 881-884, 1979.

[50] C.A. Rogasaki, J. M. Price, J. A. Mack and A. M. Wodtke. Laboratory evidence for a possible non-lte mechanism of stratospheric ozone formation, Geophysical Research Letters, Vol. 20, No. 24, 2885-2888, 1993.

[51] R. L. Miller, A. G. Suits, P. L. Houston, R. Toumi, J. A. Mack and A. M. Wodtke. The "Ozone Deficit" Problem: $\mathrm{O}_{2}\left(\mathrm{X}^{3} \Sigma_{\mathrm{g}}{ }^{-}, v \geq 26\right)+\mathrm{O}_{3}$ from 226-nm Ozone Photodissociation, Science, Vol. 265, Issue 5180, 23, 1831-1838, 1994.

[52] E. K. Gill, K. J. Laidler, Reactions involving electronically-excited oxygen, Canadian Journal of Chemistry, Vol. 36. No. 1, 79-88, 1958. DOI: https://doi.org/10.1139/v58-009

[53] C. K. Ulrich, J. Chen, O. Tokel, P. L. Houston and S. Yu. Grebenshchikov. Photodissociation of Ozone from 321 to $329 \mathrm{~nm}$ : The Relative Yields of $\left.\mathrm{O}^{3} \mathrm{P}_{2}\right)$ with $\mathrm{O}_{2}\left(\mathrm{X}^{3} \Sigma_{\mathrm{g}}{ }^{-}\right)$, $\mathrm{O}_{2}\left(\mathrm{a}^{1} \Delta \mathrm{g}\right)$ and $\mathrm{O}_{2}\left(\mathrm{~b}^{1} \Sigma_{\mathrm{g}}{ }^{+}\right)$, The Journal of Physical Chemistry, Vol. 117, Issue 46, 12011-12019, 2013. DOI: dx.doi.org/10.1021/jp4041088

[54] R. P. Wayne. Reactions of excited species in the photolysis of ozone, Faraday Discussions of the Chemical Society, Vol. 53, 172-181, 1972.

[55] R. G. W. Norrish and R. P. Wayne. The Photolysis of ozone by ultraviolet radiation 1 . The photolysis of pure dry ozone, Proceedings of the Royal Society (London), A288, 200-211, 1965.

[56] P. Hartek and R. R. Reeves, Jr. Formation and Reactions of the excited $\mathrm{O}_{2}\left(\mathrm{~A}^{3} \Sigma_{\mathrm{u}}^{+}\right)$molecules. Discussion of the Faraday Society, Vol. 37, 82-86, 1964.

[57] A. Dušan, R. A. Pejaković, T. Copeland, G. Slanger and K. S. Kalogerakis: $\mathrm{O}_{2}\left(\mathrm{~b}^{1} \Sigma_{\mathrm{g}}{ }^{+}, v=0,1\right)$ relative yields in $\mathrm{O}\left({ }^{1} D\right)+\mathrm{O}_{2}$ energy transfer. The Journal of Chemical Physics, Vol. 141, 024303, 2014. DOI: http://dx.doi.org/10.1063/1.4885721
[58] V. A. Krasnopolsky and F. Levfévre. Chemistry of the Atmospheres of Mars, Venus and Titan, Comparative Climatology of Terrestrial Planets, The University of Arizona Press, Tucson, 231-275, 2013.

[59] D. R. Bates. The Green light of the Night Sky, Planetary Space Science, Vol. 29, No. 10, 1061-1067, 1981.

[60] I. C. McDade and E. J. Llewellyn. Rocket Measurements of the $\mathrm{O}_{2}$ Infrared Atmospheric (0-0) Band in the Nightglow: The Vestigial Dayglow Components. In: Progress in Atmospheric Physics, Kluwer Academic Publishers, 151166, 1988.

[61] D. R. Bates. Airglow and Auroras. In: Applied Atomic Collision Physics, Vol. 1, Atmospheric Physics and Chemistry, Academic Press, New York, 150-153, 1982.

[62] I. M. Reid, Andrew J. Spargo and J. M. Woithe. Seasonal variations of the night-time $\mathrm{O}\left({ }^{1} \mathrm{~S}\right)$ and $\mathrm{OH}(8-3)$ airglow intensity at Adelaide, Australia, Journal of Geophysical Research: Atmospheres, Vol. 119, Issue 11, 6991-7013, 2014. DOI: 10.1002/2013JD020906

[63] J. E. Frederick, D. W. Rush, G. A. Victor, W. E. Sharp, P. B. Hays and H. C. Brinton. The OI ( $\lambda 5577$ A) Airglow: Observations and Excitation Mechanisms, Journal of Geophysical Research, Vol. 81, No. 22, 3923-3930, 1976.

[64] T. G. Slanger, P. C. Cosby, B. D. Sharpe, K. R. Minschwaner and D. E. Siskind: Ionosphere and Upper Atmosphere $\mathrm{O}\left({ }^{1} \mathrm{~S} \rightarrow{ }^{1} \mathrm{D},{ }^{3} \mathrm{P}\right)$ branching ratio as measured in the terrestrial nightglow, Journal of Geophysical Research: Space Physics, Vol. 111, Issue A12, 1-23, 2006.

[65] R. R. Meier. Ultraviolet spectroscopy and remote sensing of the upper atmosphere, Space Science Reviews, Vol. 58, p. 19, 1991. Available online:

https://asd.gsfc.nasa.gov/archive/nightglow/data.html

[66] J. M. Young, C. S. Weller, C. Y. Johnson and J. C. Holmes. Rocket observations of the far UV nightglow at Lyman $\alpha$ and shorter wavelengths, Journal of Geophysical Research, Vol. 76: Space Physics, 3710-3722, 1971. DOI: 10.1029/JA076i016p03710

[67] A. Migliorini, G. Piccioni, J. C. Gerard, L. Soret, T. G. Slanger, R. Politi, M. Snels, P. Drossart and F. Nuccilli. The characteristics of the $\mathrm{O}_{2}$ Herzberg II and Chamberlain bands observed with VIRTIS/Venus Express, Icarus Vol. 223, Issue 1, 609-614, 2013.

[68] R. G. H. Greer and D. P. Murtagh, Singlet oxygen nightglow in the atmospheres of Earth, Venus and Mars, Irish Astronomical Journal, Vol. 17, 25-30, 1985.

[69] SPACE.com Staff. Scientists Discover Ozone Layer On Venus, October 11, 2011. Available online: https://www.space.com/13244-venus-atmosphere-ozone-lay er.html 